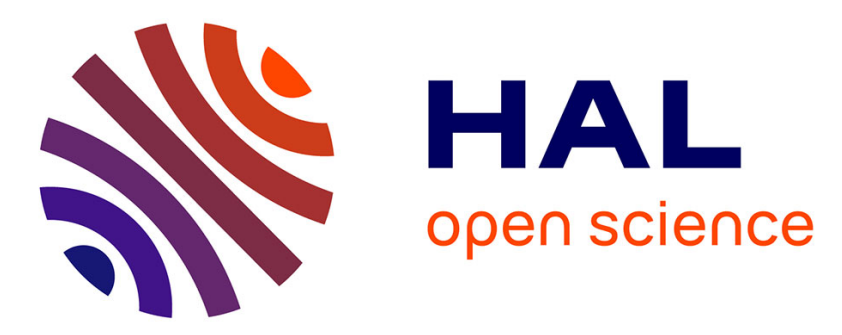

\title{
A numerical modelling of 3D polycrystal-to-polycrystal diffusive phase transformations involving crystal plasticity
}

\author{
Fabrice Barbe, Romain Quey
}

\section{- To cite this version:}

Fabrice Barbe, Romain Quey. A numerical modelling of 3D polycrystal-to-polycrystal diffusive phase transformations involving crystal plasticity. International Journal of Plasticity, 2011, 27 (6), pp.823840. 10.1016/j.ijplas.2010.09.008 . hal-00595995

\section{HAL Id: hal-00595995}

https://hal-mines-paristech.archives-ouvertes.fr/hal-00595995

Submitted on 2 Sep 2020

HAL is a multi-disciplinary open access archive for the deposit and dissemination of scientific research documents, whether they are published or not. The documents may come from teaching and research institutions in France or abroad, or from public or private research centers.
L'archive ouverte pluridisciplinaire HAL, est destinée au dépôt et à la diffusion de documents scientifiques de niveau recherche, publiés ou non, émanant des établissements d'enseignement et de recherche français ou étrangers, des laboratoires publics ou privés. 


\title{
A numerical modelling of 3D polycrystal-to-polycrystal diffusive phase transformations involving crystal plasticity
}

\author{
F. Barbe $\mathrm{a}^{\mathrm{a}, \mathrm{b}, *}$, R. Quey ${ }^{\mathrm{c}, 1}$ \\ a INSA Rouen, Groupe de Physique des Matériaux, CNRS UMR 6634 \\ 76801 Saint Etienne du Rouvray, France \\ ${ }^{b}$ Mines Paristech, Centre des Matériaux, CNRS UMR 7633 \\ 91003 Evry, France \\ ${ }^{c}$ École des Mines de Saint-Étienne, Centre SMS, CNRS UMR 5146, \\ 158 cours Fauriel, 42023 Saint-Étienne, Cedex 2, France
}

\begin{abstract}
A FE modelling of the elastoplastic interactions occuring within a 3D polycrystal subjected to diffusive phase transformation is proposed. The parent polycrystal is represented by a Voronoi tessellation, where grains differ in shape, size and crystallographic orientation. Grains of the new phase nucleate at favourable sites of the parent polycrystal then grow isotropically, following specific kinetics. This process can result in various product polycrystal morphologies where grains are distinguished by their morphologies and their crystallographic orientations, and have crystalline properties different from those of the parent grains. Application is performed on the austenite-to-ferrite transformation of a low carbon steel, by analyzing different basic cases of transformation history with different constitutive modellings. Microplasticity and its related internal stresses are shown to develop during the phase transformations and to affect significantly the elastoplasticity of the product medium.
\end{abstract}

Key words: Diffusive transformation, Crystal plasticity, 3D polycrystal, Finite elements

\section{Introduction}

Solid-state phase transformations are commonly involved in polycrystalline material elaboration processes with the aim of controlling the final mechanical properties. Different compacities between the parent and product phases of the transformation can lead to the development of microplasticity at the grain scale. When phase transformations occur in structural applications, this can results in plasticity at the scale of the bulk material, called TRansformation-Induced Plasticity (TRIP).

In any case of occurrence, the factors governing its crystallographic, morphological and thermo-mechanical features are complex combinations of alloy composition, heat treatments and mechanical loadings. This concerns particularly steels: as each phase has its own crystallographic characteristics -including $\gg$ compacity density $\triangleleft \triangleleft$ and

\footnotetext{
*Corresponding author, tel: 332329597 60, fax: 33232959704

Email addresses: fabrice.barbe@insa-rouen.fr (F. Barbe), quey@emse.fr (R. Quey)

${ }^{1}$ currently at: Sibley School of Mechanical and Aerospace Engineering, Cornell University, Ithaca, NY, 14853, USA
} 
strength, mechanical fields form at the vicinity of the interfaces between phases, which can in turn affect the driving forces for nucleation and growth and by extent the evolution of the microstructure. Although the thermodynamic framework has been well established, strong couplings between the involved mechanisms make the complete description of phase transformations in steels a very complex problem.

A large amount of experimental works have been lead to understand and explain phase transformations in a wide range of practical configurations: Lecroisey and Pineau [1972]; Olson and Cohen [1975]; Denis et al. [1987]; Kempen et al. [2002]; Offerman et al. [2003]; Gourgues [2007]; Zhang and Kelly [2009a]. The considerable set of experimental data provided by these studies, in conjunction with the continuous expansion of computation capabilities, has contributed in the advent of numerical approaches for modelling microstructural evolution: methodologies based on phase field Artemev et al. [2000]; Mecozzi et al. [2006a]; Levitas and Lee [2007]; Suiker and Turteltaub [2007]; Thiessen et al. [2007]; Ammar et al. [2009a]; Levitas et al. [2010]; Ammar et al. [2009b], level set Iwamoto et al. [2008] and cellular automaton Lan et al. [2005]; Zheng et al. [2009] are widely developed with the ultimate goal to fully reproduce solid-state transformations from the atom scale to the polycrystal scale.

The other aspect of phase transformations in steels concerns its consequences on the mechanical properties. It is mostly studied from the macroscopic viewpoint of a volume element of mechanics, with the main objective of explaining and predicting TRIP Inoue and Wang [1985]; Leblond et al. [1986]; Gautier et al. [1987]; Leblond [1989]; Fischer [1990]; Ganghoffer et al. [1993]; Videau et al. [1995]; Ganghoffer and Simonsson [1998]; Fischer et al. [2000]; Nagayama et al. [2001]; Taleb and Sidoroff [2003]; Coret et al. [2004]; Grostabussiat et al. [2004]; Meftah et al. [2007]; Wolff et al. [2007]; Mahnken et al. [2009]. Indeed, TRIP is a permanent strain occurring with the incidence of phase transformation and small external mechanical loading; its inelastic nature signifies the presence of residual stresses which can lead to important perturbations in the mechanical properties of the product material and hereby on the fatigue life of structures. As its prediction requires modelling of both phase transformation and elastoplastic fields governed by non-linear constitutive laws, its dedicated models have to resort to strong hypotheses about the phase transformation itself and its kinetics.

Gaps to be bridged between fully-coupled microstructural evolution and elastoplastic macroscopic properties of polycrystalline materials are still very large. To this day, it is possible to model the complete ferritic transformation of a $3 \mathrm{D}$ polycrystal by phase field Apel et al. [2009], but the mechanical interactions between phases are considered to be elastic. Crystal plasticity has been included in the phase-field modelling of microstructural evolution of Ni-based alloys Gaubert et al. [2009], but because of the huge amount of time required for simulations, applications are limited to single crystals. Besides, microstructure-based FE models which account for plasticity for predicting martensitic transformations in 3D polycrystals (shape memory alloys or metastable austenitic steel) have recently been proposed Manchiraju and Anderson [2010]; Lee et al. [2010]. They couple transformation and crystal plasticity in a large deformation framework but the representation of the microstructure evolution is provided in terms of volume fraction per grain of parent phase and the morphology of the polycrystals is described simply by assigning each parent grain to an integration point or a single finite element of a regular mesh.

Our recent works Barbe et al. [2005, 2008]; Hoang et al. [2007]; Quey et al. 
[2009] have introduced an alternative methodology, which consists in controlling the transformation kinetics (nucleation and growth following specific evolution laws), and resolve numerically the resulting mechanical interactions between phases. As in other works dedicated to the prediction of TRIP in a diffusively transforming material Leblond et al. [1989]; Ganghoffer et al. [1993]; Schuh and Dunand [2001]; Taleb and Sidoroff [2003]; Barbe et al. [2007], the phases were considered to be homogeneous materials differing only by their $\longrightarrow$ compacity density $4<$ and elastoplastic properties. In Barbe et al. [2008], a methodology has been provided for determining representative properties of a transforming heterogeneous material from ensemble averaging over randomly extracted sub-domains.

In the present study, the modelling is extended to the case of a polycrystalline medium with random microstructural morphology, in which grain constitutive behaviours are governed by crystal plasticity. This modelling is denoted $P X 2 P X$ so as to refer to the modelling of Polycrystal-to-Polycrystal transformations and their consequences. It provides insight into the elastoplastic interactions resulting from phase transformation, at the inter- and intracrystalline scale of 3D polycrystal and thus enables to examine their contributions on the effective mechanical properties.

The aim of this paper is twofold: (i) to lay the foundations of a methodology which will be assessed in the future at the lights of experimental investigations; (ii) to demonstrate the capabilities of the modelling through applications at different scales and at the same time to analyse mechanical interactions accompanying phase transformations $\longrightarrow$ in a model configuration of polycrystalline microstructure evolution. 44 The paper is accordingly organised in two main parts. Section 2 , introduces the modelling in the general case of diffusive transformations in crystalline materials: it is subdivided into Sections 2.1 and 2.2 dedicated respectively to phase transformation modelling (microstructure, kinetics, meshing) and to constitutive laws. Section 3 presents the application of the modelling to the study of the austenite-toferrite transformation in a low carbon steel: after the complete description of the case of study (loading conditions, material and mesh) in Sections 3.1 and 3.2, analyses at the local and global scales are presented in Section 3.3. Conclusions are then drawn on the potential of the modelling and on the most striking results of analyses.

\section{Modelling}

\subsection{Phase transformations}

The phase transformations under concern in this study are diffusive phase transformations that occur in polycrystals through the processes of nucleation then growth. Their modelling involves a proper representation of the parent medium, and of the transformation kinetics.

\subsubsection{Parent polycrystal}

In the present work, the parent polycrystal is represented by a Voronoi tessellation, constructed from a random distribution of points ("Poisson-Voronoi" tessellations), and each grain is assigned a random crystallographic orientation. Voronoi tessellations enable to account for the irregularity of the microstructure of polycrystalline materials, including variations in grain volume and shape. Such morphologies have been used for various finite element studies of the plasticity of polycrystals Canova et al. [1992]; Barbe et al. [2001a]; Nygards and Gudmundson [2002]; Zhao and Tryon [2004]; 
Diard et al. [2005]; Zeghadi et al. [2007]; Osipov et al. [2008]; Lebensohn et al. [2009]; Musienko and Cailletaud [2009] as well as phase-field modellings of phase transformations Mecozzi et al. [2006ba]; Apel et al. [2009]. Accounting for the irregularity of microstructures is particularly justified when it is desired to study local phenomena. Here, this provides not only realistic physical representation of the parent polycrystal, but also of the distribution of nucleation sites which are located at specific locations in the parent microstructure - statistical data on nucleation site distributions have been provided in Barbe et al. [2008].

It should also be stressed, after Barbe et al. [2008], that two distinct space domains are actually used in the modelling: one for the calculation of the mechanical fields, and the other (bigger) for the simulation of the phase transformation. Indeed, as the domain used for calculating the mechanical fields resulting from phase transformation is viewed as an inner volume of a (much bigger) piece of material, its transformation can be affected by the growth of grains which nucleate in its direct neighbourhood. By construction, the domain used to simulate the transformation must be large enough so as to include all nucleation sites susceptible to influence the transformation.

\subsubsection{Nucleation}

Following classical notions of phase transformation theory, the nucleation tends to occur at particular locations of the parent phase, where imperfect atom arrangements favour their formation. In a polycrystal, these locations are the grains corners, edges and surfaces (also sometimes called quadruple points, triple lines and grain boundaries), in descending order of preference. The nucleation on such sites is denoted as "heterogeneous" as opposed to the much more unlikely "homogeneous nucleation", which would take place in the bulk of the grains. This tendency has been confirmed experimentally by an in situ analysis of phase transformation performed by Offerman et al. Offerman et al. [2006]. Other works report some rate of nucleation in the bulk of the grains in the case where the material has been previously strain hardened (the grains show subgrain structures that favour nucleation) Landheer et al. [2009].

Contrary to the quadruple points which are in finite number in the microstructure, the triple lines, grain boundaries and grain interiors show a nearly infinite number of potential nucleation sites. For the modelling, they are reduced to finite sets which are obtained by mapping them on a regular grid (the one used for the meshing, see Section 2.1.4). This is illustrated on Fig. 1 for the case of a polycrystal made of a few grains. On Fig. 1, as explained previously, while the central cube stands for the volume used for the simulation of the mechanical fields, new grains can nucleate / grow from all the nucleation sites embedded in the (much bigger) dashed box. Each nucleation site family can be assigned a specific nucleation rate.

In principle, the crystallographic orientation of a germ of new phase can be related to the orientation properties of the parent medium where it nucleates. Such relationships are particularly present in the case of displacive transformations Gourgues [2007], where the Kurdjumov-Sachs and Nishiyama-Wassermann relationships generally apply for bainitic and martensitic transformations. To our knowledge, such relationships do not exist for diffusive transformations, and it has been shown in Zhang and Kelly [2009b] for the pearlitic transformation of a Hadfields steel that the orientation of a pearlitic ferrite grain is not correlated to the one of the austenite grain it consumes. Consequently, in the present work, the crystallographic orientations of the ferrite grains are set randomly. 


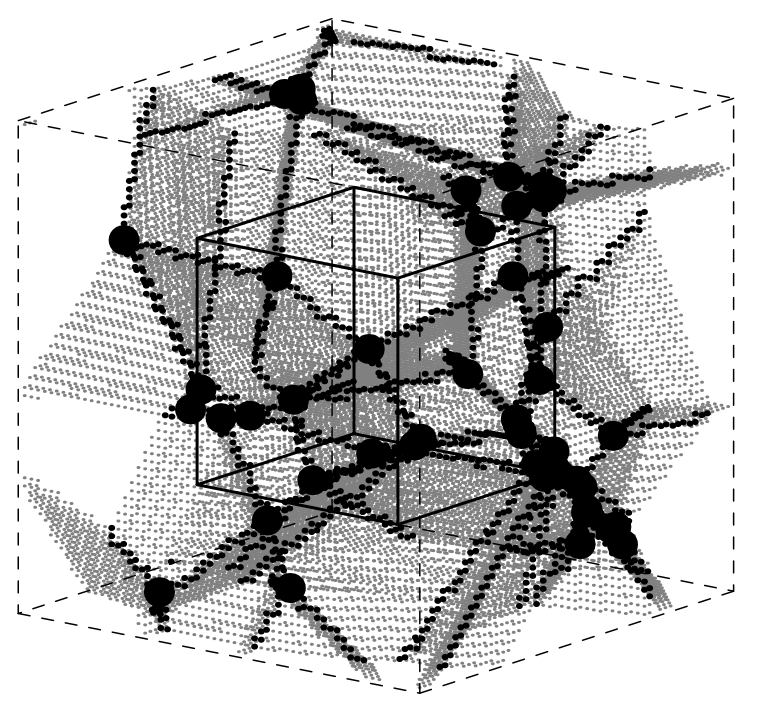

Figure 1: Distribution of heterogeneous-nucleation sites in a polycrystalline medium at grain corners (large spheres), edges (small black spheres) and surfaces (grey spheres). The in-grain sites are not represented for clarity. The central cube represents the volume considered for the FE simulation.

\subsubsection{Growth}

An extensive bibliographic analysis of Gourgues Gourgues [2007] reports various observations concerning diffusive transformations in steels, which converge towards a single feature: the growth rate can be significantly affected by the disorientation between ferrite and the austenite grain into which it is growing, thus resulting in anisotropic growth. To our knowledge, there is no available quantified information about this phenomenon, though. The same complexity has been reported for the case of grain growth in aluminium Schmidt et al. [2008]. Consequently, in the present work, this effect is not accounted for: the growth rate is supposed to be uniform in the aggregate, and isotropic. Figures 2, 3 and 4 illustrate the case of phase transformations governed by different nucleation and growth laws. In the three cases, nucleation takes place at the quadruple points of the parent polycrystal, but it is shown that different transformation kinetic laws can lead to very different polycrystal morphologies.

\subsubsection{Meshing}

While techniques are available for generating unstructured meshes of large-scale Voronoi tessellations (tetrahedral elements) Quey and Barbe [2007]; Neper [2007]; Barbe et al. [2009], the case where phase transformations occur appears more complicated and may even need the use of heavy remeshing methods.

In the present work, the microstructure is discretized regularly into brick elements, resulting in irregular grain boundaries, which do not necessarily match the real morphology. However, it is shown in the following that, provided a fine enough mesh (in terms of average number of element per grain), the mapped meshing technique does not influence the investigated phenomena.

The phase transformation formulation has been implemented in the software Neper Neper [2007], which provides the data necessary for the finite element simulations. 


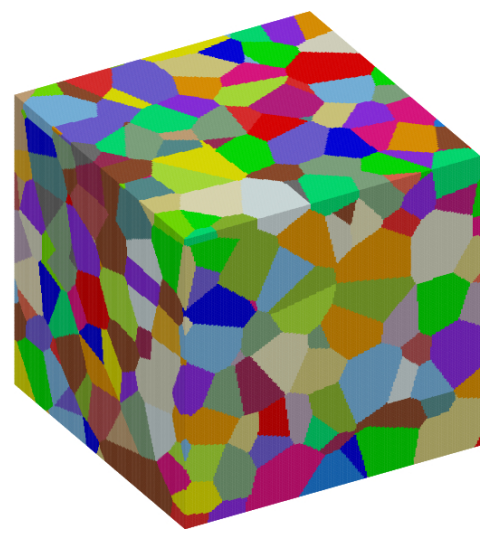

Voronoi; $t=0 \mathrm{~s}, z=0$

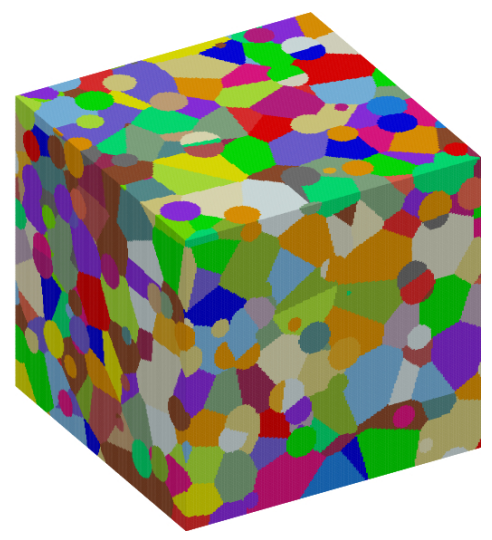

$t=3 \mathrm{~s}, z=22 \%$

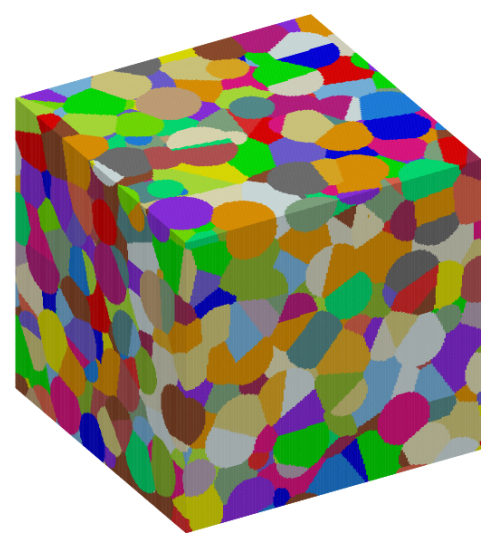

$t=5 \mathrm{~s}, z=70 \%$

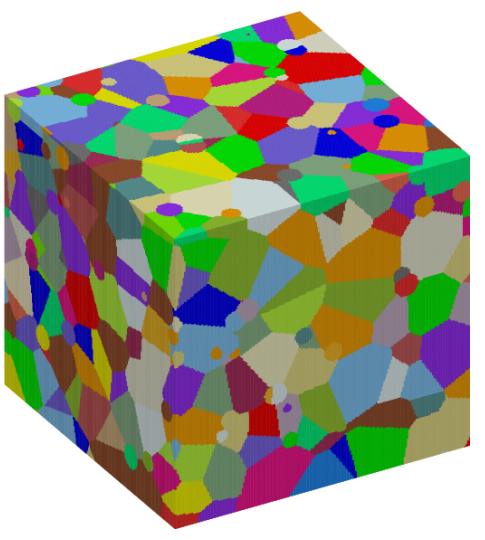

$t=2 \mathrm{~s}, z=7 \%$

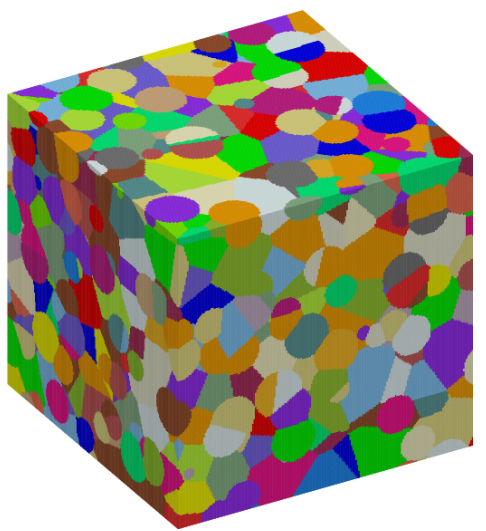

$$
t=4 \mathrm{~s}, z=45 \%
$$

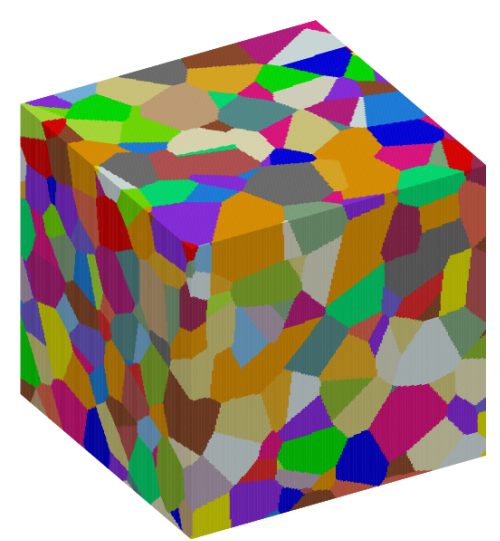

$$
t=11 \mathrm{~s}, z=100 \% \text {; Voronoi }
$$

Figure 2: Evolution of the microstructure during the transformation from a Voronoi tessellation; nucleation at grain corners at $t=0: 1$ germ / grain; constant growth velocity. $\gg z$ denotes the volume fraction of product phase. 44 

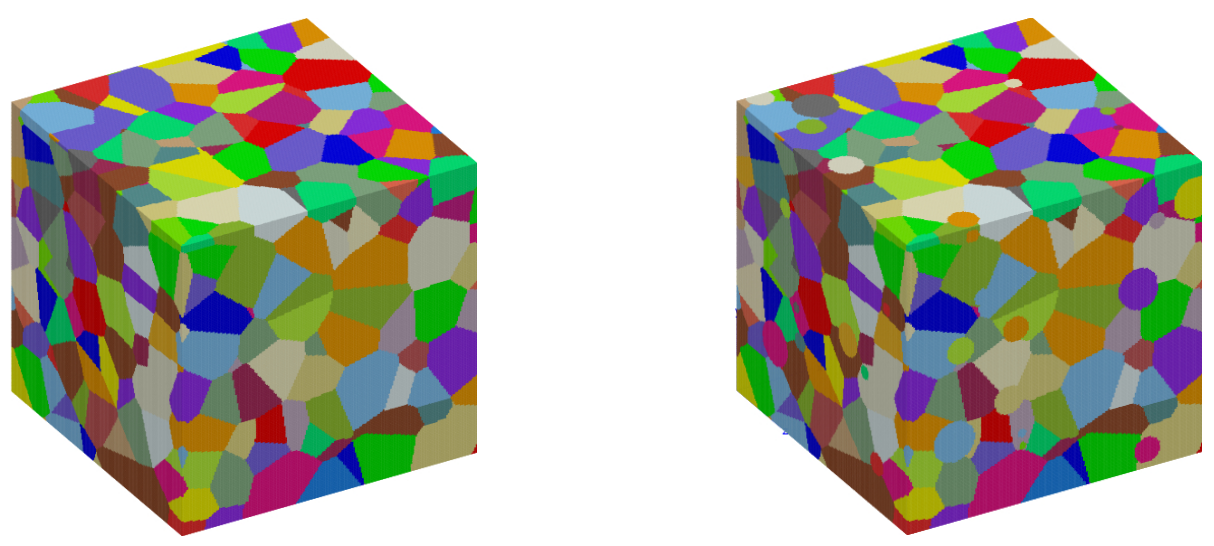

Voronoi; $t=0 \mathrm{~s}, z=0$

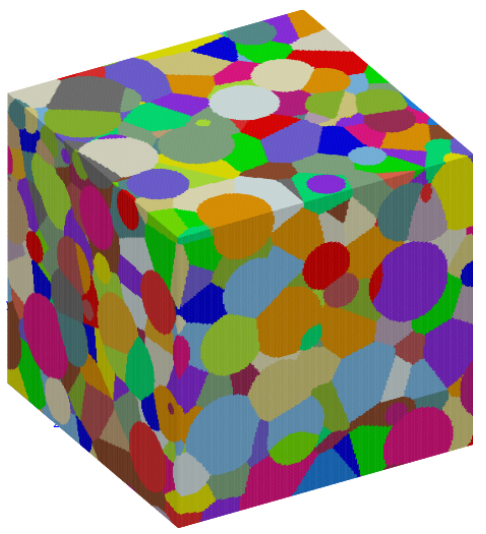

$t=6 \mathrm{~s}, z=27 \%$

$$
t=7 \mathrm{~s}, z=45 \%
$$
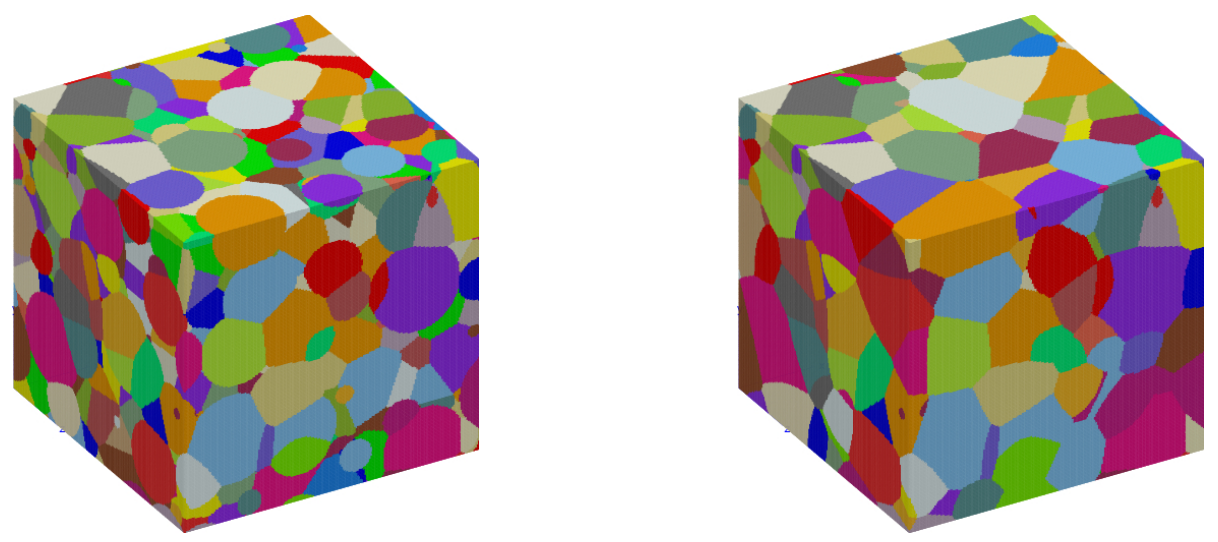

$$
t=15 \mathrm{~s}, z=100 \% \text {; Johnson-Mehl }
$$

Figure 3: Evolution of the microstructure during the transformation from a Voronoi tessellation; nucleation at grain corners through time: 0.1 germ. $\mathrm{s}^{-1} /$ grain; constant growth velocity. $\gg z$ denotes the volume fraction of product phase. 44 


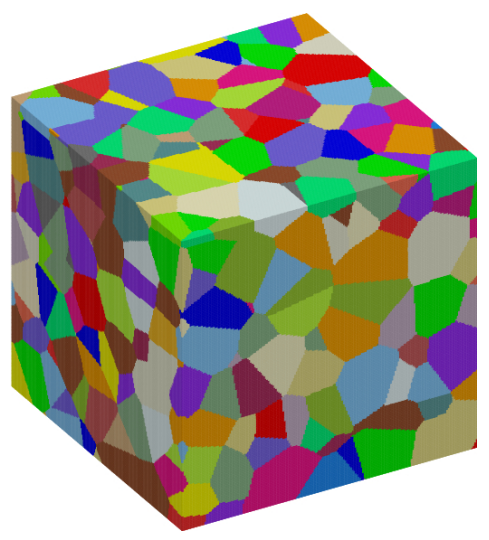

Voronoi; $t=0 \mathrm{~s}, z=0$; a few nuclei

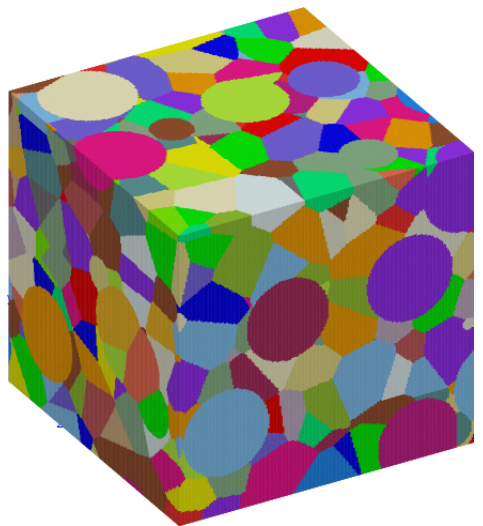

$t=9 \mathrm{~s}, z=24 \%$; same number of nuclei $t=14 \mathrm{~s}, z=47 \%$; same number of nuclei

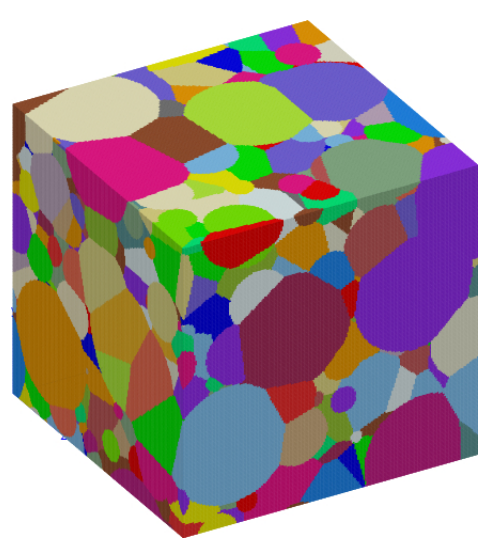

$$
t=17 \mathrm{~s}, z=75 \% \text {; site saturation }
$$

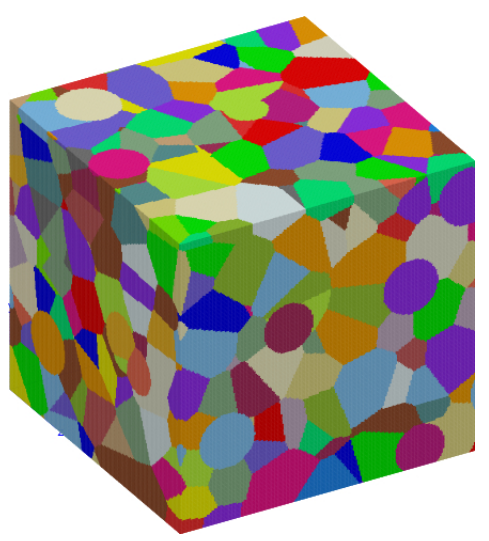

$t=4 \mathrm{~s}, z=9 \%$; same number of nuclei
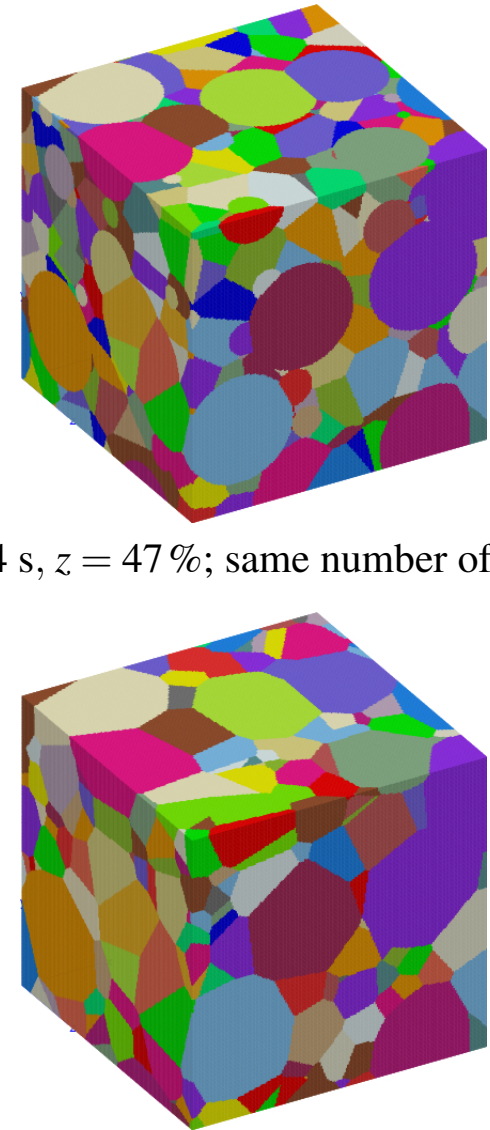

$$
t=26 \mathrm{~s}, z=100 \% \text {; irregular }
$$
microstructure

Figure 4: Evolution of the microstructure during the transformation from a Voronoi tessellation; irregular nucleation at grain corners: $0.05+10^{-12} t^{10}$ germ / grain; variable growth velocity $(r=0.05 \sqrt{t}) . \rightarrow z$ denotes the volume fraction of product phase. 44 


\subsection{Constitutive laws}

The material behaviour formulation used in this study is based on the constitutive model introduced in Méric et al. [1991]. It is implemented in the finite element code Z-set / Zébulon (Mines Paristech, ONERA, nwnumerics.com, Besson et al. [1998]) and has already been used for the study of the plastic deformation of a wide range of polycrystalline materials: see for example Barbe et al. [2001a]; Diard et al. [2005]; Sai] et al. [2006]; Osipov et al. [2008]; Musienko et al. [2007]; Gérard et al. [2009]. The formulation is extended in this work to account for phase transformations.

\subsubsection{General framework}

In the case of coexistent elastoplastic strain and phase transformation, the (total) strain $\underset{\sim}{\mathcal{E}}$ can be additively decomposed into three components:

$$
\underset{\sim}{\mathcal{E}}={\underset{\sim}{\mathcal{E}}}^{e}+{\underset{\sim}{\mathcal{E}}}^{p}+{\underset{\sim}{\mathcal{E}}}^{t r}
$$

where $\underset{\sim}{\mathcal{\varepsilon}}{ }^{e}$ is the elastic strain, $\underset{\sim}{\varepsilon}{ }^{p}$ is the viscoplastic strain, and ${\underset{\sim}{\varepsilon}}^{t r}$ is the phase transformation strain.

The elastic strain $\underset{\sim}{\mathcal{E}}{ }^{e}$ is related to the Cauchy stress $\underset{\sim}{\sigma}$ through the fourth-order Hooke tensor $\mathbf{C}$ :

$$
\underset{\sim}{\sigma}=\underset{\sim}{\mathbf{C}}:{\underset{\sim}{\varepsilon}}^{e}
$$

The viscoplastic strain $\underset{\sim}{\underset{\varepsilon}{p}}$ can be related to the slips $\gamma^{\mathrm{s}}$ on the crystallographic slip systems $\gg$ of the considered slip system family $\triangleleft<$ through the symmetric Schmid tensors $\mathbf{m}^{\text {s }}$ (eq. 3 ).

$$
\dot{\sim}^{\mathrm{p}}=\sum_{s} \mathbf{m}_{\sim}^{\mathrm{s}} \dot{\gamma}^{\mathrm{s}} \quad \text { with } \quad{\underset{\sim}{\mathbf{m}}}^{\mathrm{s}}=\frac{1}{2}\left(\underline{n}^{\mathrm{s}} \otimes \underline{l}^{\mathrm{s}}+\underline{l}^{\mathrm{s}} \otimes \underline{n}^{\mathrm{s}}\right)
$$

where $\underline{l}^{\mathrm{s}}$ and $\underline{n}^{\mathrm{s}}$ are the slip direction and the normal of the slip plane of slip system $s$ (unit vectors).

The plastic flow $\dot{\gamma}$ is defined in the classical viscoplastic framework, with resolved shear stress $\tau^{\mathrm{s}}$ taken as the critical variable: slip takes place on a system $s$ provided that $\tau^{\mathrm{s}}$ is greater than $x^{\mathrm{s}}+r^{\mathrm{s}}$ or less than $x^{\mathrm{s}}-r^{\mathrm{s}}$, where $r^{\mathrm{s}}$ and $x^{\mathrm{s}}$ represent isotropic and kinematic hardening, respectively (eq. 4). While $\tau^{\mathrm{s}}$ is related to the stress $\sigma$ through the Schmid tensor $\mathbf{m}_{\sim}^{\mathrm{s}}$ (eq. 5), the hardening variables follow non-linear evolutions defined by classical phenomenological formulations of hardening (eq. 6.and 7).

$$
\begin{gathered}
\dot{\gamma}^{\mathrm{s}}=\dot{v}^{\mathrm{s}} \operatorname{sign}\left(\tau^{\mathrm{s}}-x^{\mathrm{s}}\right) \quad \text { with } \quad \dot{v}^{\mathrm{s}}=\left\langle\frac{\left|\tau^{\mathrm{s}}-x^{\mathrm{s}}\right|-r^{\mathrm{s}}}{K}\right\rangle^{n} \\
\tau^{\mathrm{s}}=\underset{\sim}{\sigma}:{\underset{\sim}{\mathbf{m}}}^{\mathrm{s}} \\
x^{\mathrm{s}}=c \alpha^{\mathrm{s}} \quad ; \quad r^{\mathrm{s}}=r_{0}+Q \sum_{r} h_{r s}\left(1-e^{-b v^{\mathrm{r}}}\right) \\
\dot{\alpha}^{\mathrm{s}}=\dot{\gamma}^{\mathrm{s}}-d \alpha^{\mathrm{s}} \dot{v}^{\mathrm{s}}
\end{gathered}
$$

In this formulation, $\langle x\rangle=\operatorname{Max}(x, 0)$. The initial conditions are: $v^{\mathrm{s}}\left(t=t_{0}\right)=0$ and $\alpha^{\mathrm{s}}\left(t=t_{0}\right)=0$. 
Crystallographic slip occurs on different systems for the parent and product phases. Austenite has an FCC structure, with slip on the $\left\{\begin{array}{lll}1 & 1 & 1\end{array}\right\}\langle 110\rangle$ octahedral slip systems, and ferrite has a BCC structure, with slip on the $\{110\}\langle 111\rangle$ and $\{112\}\langle 111\rangle$ slip systems, following Franciosi [1985].

The transformation strain $\mathcal{\varepsilon}^{t r}$ is related to the interphase region, which further has a mechanical behaviour different from those of the parent and product phases. This is detailed in the following.

\subsubsection{Interphase region}

In a physical system, the interphase region is reduced to the very thin area where atoms rearrange between the old and new phases, and which propagates through transformation. In our simulation, the interphase region is accounted for by the successive layers of elements between the parent and product phases, whose transformation from the parent to the product phases occurs through changes in volume density, constitutive behaviour, and crystallographic orientation.

As for the transformation strain ${\underset{\sim}{t r}}^{t r}$ associated to the transformation of the interphase region, it can be simply seen, in the case of the diffusive transformations under concern, as a dilation:

$$
{\underset{\sim}{t r}}^{t r}=\varepsilon^{t r} \underset{\sim}{\mathbf{1}}
$$

where $\underset{\sim}{\mathbf{1}}$ is the identity tensor and $\varepsilon^{t r} \Rightarrow 1.00420 .0042 \triangleleft<$ for the austenite-to-ferrite transformation under concern in the application of Section 3 .

The constitutive behaviour of any element of the interphase region through its transformation must involve some combination of the behaviours of the parent and product phases, and be equal to the former and latter at the beginning and end of its transformation, respectively. While this can be quite straightforward to account for in the case of homogeneous phases $\gg$ (see Barbe et al. [2007] for details) $\triangleleft 4$, the case of crystalline phases requires particular care since it involves different slip systems as well as different crystallographic orientations in the parent and product grains.

In the interphase region, both the parent and product slip systems geometries (FCC and BCC systems) -in their respective coordinate systems- are accounted for. $\gg$ Let $s_{u}$ denote the slip systems of the slip system family $u$. In this configuration of multiple slip system families, related or not to different crystallographic orientations, the plastic strain rate at an integration point and all along the transformation is given by

$$
{\underset{\sim}{\dot{\varepsilon}}}^{\mathrm{p}}=\sum_{u} \sum_{s} \mathbf{m}^{\mathrm{s}_{\mathrm{u}}} \dot{\gamma}^{\mathrm{s}_{\mathrm{u}}}
$$

The transition from the parent to the product phase through the element transformation consists in inhibiting the slip rate $\dot{\gamma}^{\dot{s}_{u}}$ according to the slip system family which must be inactive. $४ 4$ This is handled by varying the critical resolved shear stresses $r_{0}^{t r}$ of the different slip system families. They are imposed to vary according to power laws such that,

$$
r_{0}^{t r}(t)=\min \left(r_{0}^{\text {old }}(t), r_{0}^{\text {new }}(t)\right)
$$

where

$$
r_{0}^{\text {old }}(t)=\left(r_{0}^{\infty}-r_{0}^{\text {old }}\right) / \Delta t^{n^{\text {old }}} \times\left(t-t_{0}\right)^{n^{\text {old }}}+r_{0}^{\text {old }}
$$




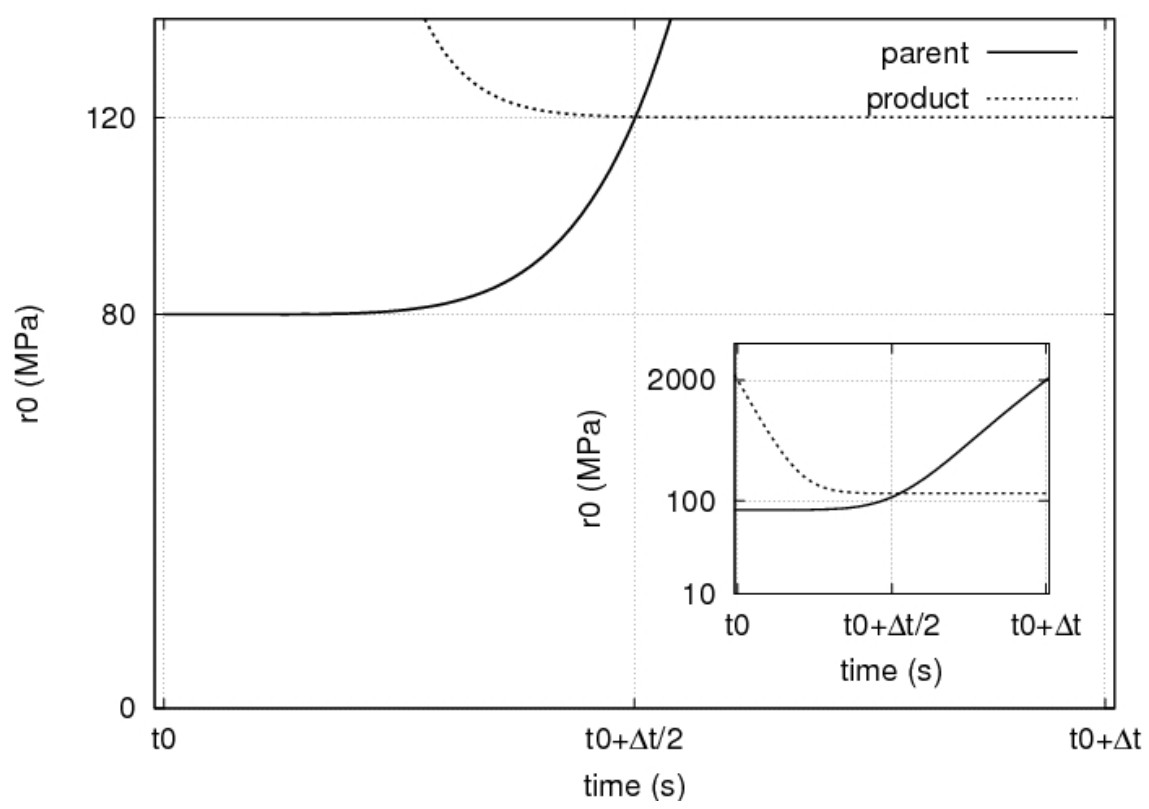

Figure 5: Variation of the critical resolved shear stress $r_{0}^{t r}(t)$ during the transformation of a FE, between $t_{0}$ and $t_{0}+\Delta t$. The inset provides the full scale curves.

$$
r_{0}^{\text {new }}(t)=\left(r_{0}^{\infty}-r_{0}^{\text {new }}\right) / \Delta t^{n^{\text {new }}} \times\left(t_{0}+\Delta t-t\right)^{n^{\text {new }}}+r_{0}^{\text {new }}
$$

$r_{0}^{\infty}$ is arbitrarily set as high as to consider that no slip occurs with this critical resolved shear stress. $t_{0}$ and $t_{0}+\Delta t$ are the respective instants of the start and end of the transformation of the considered FE. $n^{\text {old }}$ and $n^{\text {new }}$ are chosen such that $r_{0}^{\text {tr }}(\Delta t / 2)=$ $r_{0}^{\text {new }}$. With the parameters of the application of Section 3 , corresponding to an austeniteto-ferrite transformation, $\rightarrow$ the equations 8 and 9 lead to the curves of Fig. 5 .

In order to evaluate the influence of the transition parameters on the mechanical fields, another set of values has been tested, such that the critical resolved shear stresses of both slip families be much higher than $r_{0}^{\text {old }}$ and $r_{0}^{\text {new }}$ during most of the transformation of an element. Doing so, slip activity in the transforming element is prevented, which as a consequence disables any contribution of the interphase layer in the plasticity of the polycrystal. On the mean scale of polycrystals, no significant difference arises between the two configurations. Only slight quantitative differences on the local stress and strain field could be noticed. Since only the initial and final values matter, it can further be concluded that the mesh is fine enough (the relative volume of the interphase layer is negligible when compared to those of the parent / product phases).

\section{Application}

The introduced modelling enables to simulate mechanical tests on a representative volume element of a polycrystalline medium before, during and after transformation. At the same time, it provides access to the local fields at the intracrystalline scale of the transforming polycrystal. The applications are meant to address the problem of interactions between elastoplasticity and phase transformation at two scales which are classically under concern in FE simulations of polycrystals: (i) that of the apparent or macroscopic properties of a polycrystal, which if the polycrystal is representative, provides effective properties that can be compared to those obtained from a specimen of 
a classical mechanical testing machine; (ii) that of the local intra- and inter-crystalline fields where the elastoplastic interactions and the related dislocations structures can affect significantly the driving forces for nucleation and growth, thus playing a major role on the microstructural evolution.

\subsection{Different cases of loading conditions}

For all the simulations, the external loading is stress controlled, either to maintain a zero stress such as to let the transformation and its accompanying elastoplasticity be free of any external solicitation, or to impose a simple tensile or compression load. In the latter case, as one face of the cubic domain is imposed to remain on its initial plane (displacements normal to the face are set to zero), the opposite one is where axial stress is applied.

Local interactions. For the analysis of local interactions induced by the transformation, a simple free-dilatometry test is performed. It consists in imposing the transformation while letting the external faces of the domain be free to move and to deform such as to maintain a zero average stress in the domain.

Effect of history on the apparent properties. For the analysis of apparent properties, the model is applied to study the effect of transformation and mechanical history of a product material on its elastoplastic properties. Indeed, this question remains open to debate from the experimental as well as modelling points of view: most frequently, the analyses of pre-hardening effects concern the kinetics of transformation, but not the elastoplastic properties. The works of Taleb and Petit Grostabussiat et al. [2004]; Taleb and Petit [2006] constitute exceptions as experimental studies: the elastoplastic properties of a 16MND5 steel (French AFNOR standard, equivalent to ASTM A508 low carbon steel) subjected to phase transformation has been characterized to address the question of hardening inheritance. Two main observations have been made concerning the consequences of a tensile pre-hardening (hardening applied prior to transformation). (i) Whereas it induced a significant amount of plastic strain (TRIP) in the direction of the pre-hardening tension during a martensitic transformation, it induced plastic strain in the opposite direction during a bainitic transformation (both transformations occurring free of external loading). (ii) Whereas the pre-hardening of austenite appeared to be erased by the martensitic transformation, part of it was transmitted to bainite during a bainitic transformation, which shows that diffusive transformations may not systematically erase the mechanical history of the material. As these transformations involve displacive mechanisms, the phenomena resulting from a pre-hardening followed by a purely diffusive transformation can be expected to differ, but they might be more similar to those related to the bainitic transformation than to those arising from the (purely displacive) martensitic transformation.

The application proposed in this work intends to show how the properties of a product material, obtained from a purely diffusive transformation can be affected by its mechanical or transformation history. To this purpose, the tensile properties of a product material which has undergone four different mechanical and metallurgical histories are characterized. One may equivalently consider this problem as that of four polycrystals / specimens, with the same microstructure and constitutive laws, but different mechanical and metallurgical histories. These different cases of histories are denoted virgin, FDT, CTRIP, PH: 
- virgin: no history for the product material; it corresponds to a virgin specimen which is subjected to the tensile test starting from a zero internal stress and strain field;

- FDT: the product material is the result of a transformation without any external stress, as for a Free-Dilatometry Test;

- CTRIP: the product material is the result of a transformation under a small constant externally-applied stress which is removed at the end of the transformation, as for a classical TRIP test (see details in the next paragraph);

- $P H$ : the product material is the result of the transformation under zero external stress of a parent material which has been Pre-Hardened. The pre-hardening consists in a simple tension followed by elastic unloading to zero external stress.

Transformation-induced plasticity (TRIP). The model is also applied to study the development of TRIP. This permanent strain is classically observed at the end of a transformation during which a small constant stress -inferior to the yield stresses of the constituents- has been imposed. It requires dedicated constitutive laws of plasticity for its prediction, as indicated in introduction, and can be difficult to reproduce by modelling in some loading cases. The analysis of TRIP is of particular interest since the present modelling is, to our knowledge, the first ever which can provide predictions of TRIP by accounting for both crystal plasticity and realistic microstructural morphology of a $3 \mathrm{D}$ polycrystal.

\subsection{Material and mesh discretization}

Mechanical properties. The model is applied to the austenite-to-ferrite transformation of a low-carbon steel under isothermal conditions and with no viscosity effects. These simplifications are motivated, in this preliminary analysis, by the need to minimize the number of mechanisms involved in the mechanical interactions due to phase transformation. The model will in fine be evaluated by comparison to experimental measures at the macroscopic scale.

The elastoplastic stress-strain behaviour of the transforming material is described for both phases by tension-compression curves in Fig. 6a. As the type of hardening has been shown to be of great importance for the prediction of TRIP with models based on the Greenwood-Johnson mechanism Leblond [1989]; Taleb and Petit [2006]; Barbe et al. [2007], two extremal cases have been used: a purely isotropic hardening, for which the yield surface keeps centred on zero stress and expands isotropically, and a purely kinematic hardening, for which the yield surface only shifts. The stressstrain curves (Fig. 6a) have been obtained from a 343-grain polycrystal discretized into $32 \times 32 \times 328$-node brick elements. According to several previous studies Barbe et al. [2001a c]; Diard et al. [2005], this number of grains and the associated mesh are adequate to determine effective elastoplastic properties of a polycrystalline medium such as steels. The chosen type of elements conforms with that of the phase transformation simulations.

The curves obtained from Polycrystal-to-Polycrystal $(P X 2 P X)$ simulations have been used as a reference to identify the parameters of two Macro-Homogeneous $(\mathrm{MH})$ elastoplastic laws: one with nonlinear isotropic hardening $R$ (eq. 10), and the other with nonlinear kinematic hardening $\underset{\sim}{\mathbf{X}}$ (eq. 11); their stress-strain curves are presented 


\begin{tabular}{|c|c|c|c|c|c|c|c|c|}
\hline Material & \multicolumn{3}{|c|}{ Cubic elasticity } & \multicolumn{5}{|c|}{ Slip systems } \\
\hline Isotropic hard. & $C_{1111}$ & $C_{1122}$ & $C_{1212}$ & $r_{0}$ & $Q$ & $b$ & $n$ & $K$ \\
\hline Austenite & 154 & 122 & 77 & 80 & 100 & 7 & 12 & 15 \\
\hline Ferrite & 195 & 126 & 102 & 120 & 160 & 25 & 12 & 15 \\
\hline Units & $\mathrm{GPa}$ & $\mathrm{GPa}$ & $\mathrm{GPa}$ & $\mathrm{MPa}$ & $\mathrm{MPa}$ & - & - & $\operatorname{MPa} . s^{\frac{1}{n}}$ \\
\hline$\underline{\text { Kinematic hard. }}$ & $C_{1111}$ & $C_{1122}$ & $C_{1212}$ & $r_{0}$ & $C$ & $D$ & $n$ & $K$ \\
\hline Austenite & 154 & 122 & 77 & 80 & 2000 & 20 & 12 & 15 \\
\hline Ferrite & 195 & 126 & 102 & 120 & 8960 & 56 & 12 & 15 \\
\hline Units & $\mathrm{GPa}$ & $\mathrm{GPa}$ & $\mathrm{GPa}$ & $\mathrm{MPa}$ & $\mathrm{MPa}$ & - & - & MPa. $s^{\frac{1}{n}}$ \\
\hline
\end{tabular}

Table 1: Parameters of the crystalline constitutive laws (eq. $3 \cdot 7$.

in Fig. 6p. "Macro-homogeneous" stands for the classical phenomenological modelling of elastoplasticity that considers a material volume element from the macroscopic viewpoint and accordingly assumes its homogeneity. These laws are used in the same configuration of modelling as in the works Barbe et al. [2007]; Hoang [2008]: it represents the basic modelling of the Greenwood-Johnson mechanism, with a single spherical homogeneous particle growing and interacting with a homogeneous matrix. According to the extensive analysis presented therein, this modelling enables to reproduce the main features of classical TRIP tests, and so is also used here to provide reference data.

$$
\begin{gathered}
\frac{d R}{d t}=b(Q-R) \frac{d p}{d t} \\
\frac{d \underset{\sim}{d t}}{d t}=\frac{2}{3} C \frac{d \mathcal{\sim}^{p}}{d t}-D \underset{\sim}{\mathbf{X}} \frac{d p}{d t}
\end{gathered}
$$

where $p$ stands for the accumulated equivalent plasticity, $\mathcal{\varepsilon}^{p}$ is the plastic strain and $(Q, b, C, D)$ are material parameters. The von Mises criterion is used. Hence the yield function is written $f(\underset{\sim}{\sigma}, R, \underset{\sim}{\mathbf{X}})=J_{2}(\underset{\sim}{\sigma}-\underset{\sim}{\mathbf{X}})-R$, where $J_{2}(\underset{\sim}{\sigma})$ defines the von Mises equivalent stress. The remaining parameters are thus $E, v$ and $\sigma_{y}$, respectively the Young modulus and Poisson coefficient for isotropic elasticity, and the yield stress under uniaxial tension.

The parameters of the crystal constitutive laws are provided in table 1 for elasticity and slip systems activity. Their viscosity parameters have been set such as to minimize the rate sensitivity. Table 2 provides the coefficients of the interactions matrices $h_{s r}^{\text {bcc110 }}$ and $h_{s r}^{\mathrm{bcc} 112}$. Their values are derived from the numerical study of Osipov et al. on the plasticity of ferritic steels Osipov et al. [2008], and considered to be the same for the $\{111\}\langle 110\rangle$ slip systems of austenite and $\{110\}\langle 111\rangle$ slip systems of ferrite. The parameters for $\mathrm{MH}$ laws are given in table 3 .

Transformation strain. The value of the transformation strain $\varepsilon^{t r}$ is set to 0.0042 , which is of the order of actual transformation strains for austenite-to-ferrite transformations. A volume of 1 is thus changed to a volume of $\gg 1.00421 .0126 \triangleleft$ by the transformation.

Parent microstructures and kinetics. The simulations have been performed on polycrystals containing different number of parent grains, from 30 for the analysis of 


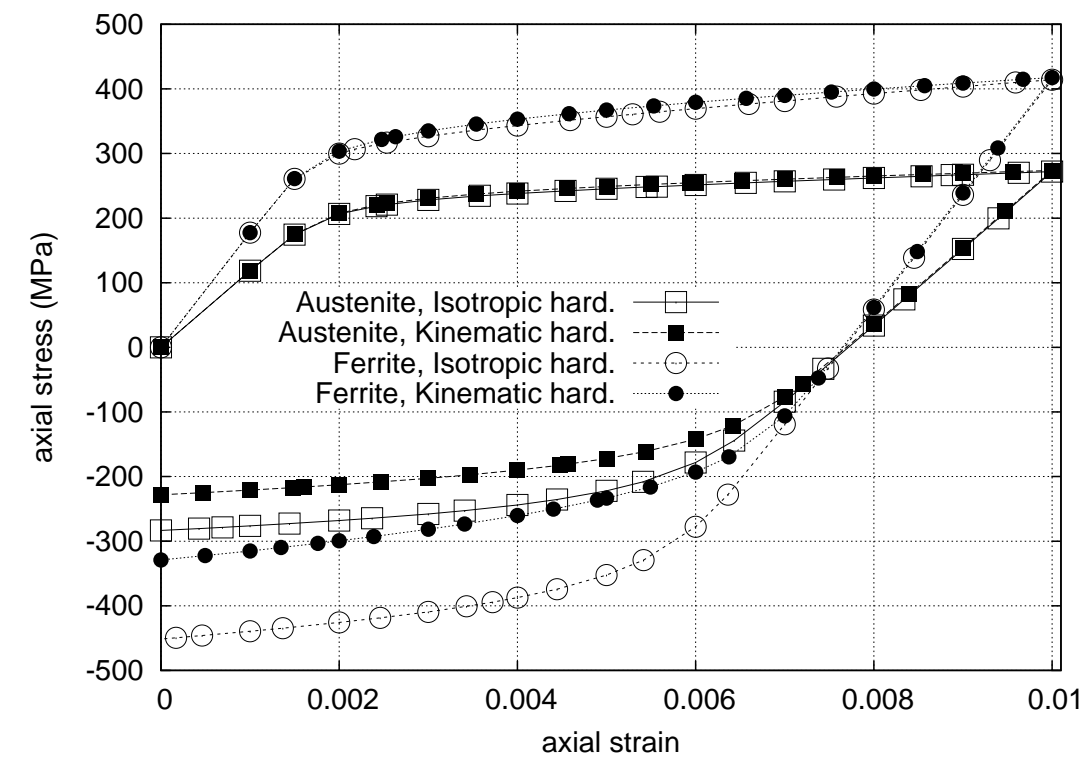

(a)

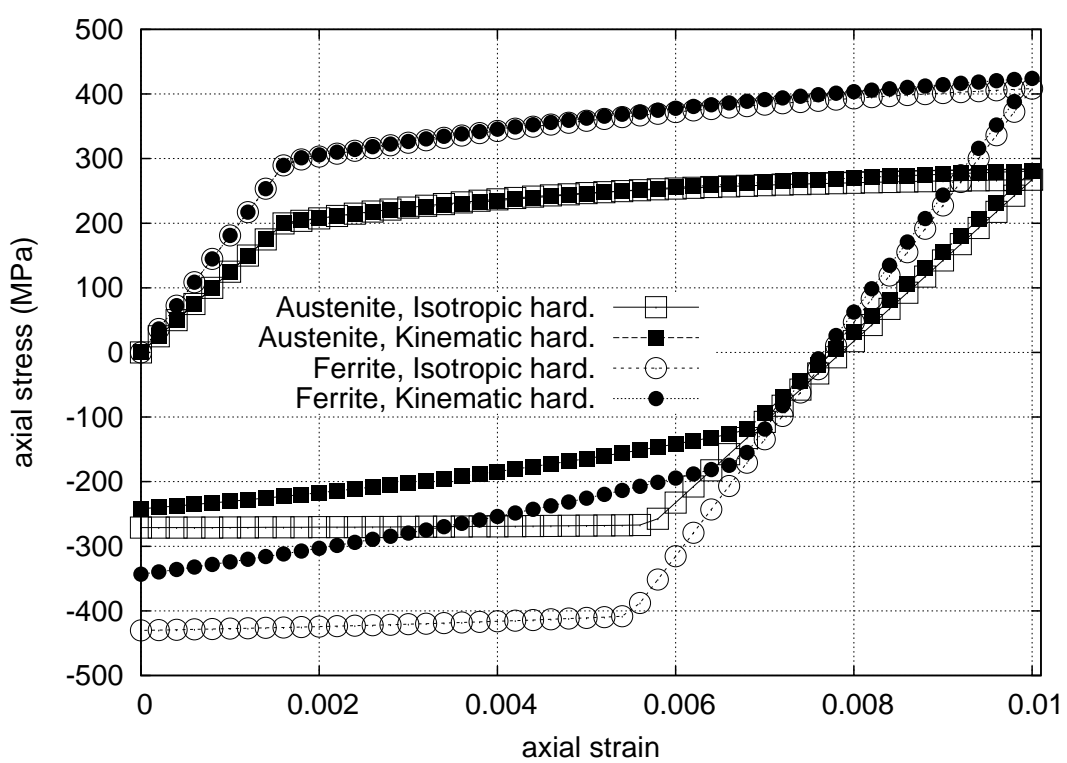

(b)

Figure 6: Stress-strain curves for austenite and ferrite under tension followed by compression. (a) Simulations on a 343-grain polycrystal. (b) Simulations with macro-homogeneous (MH) constitutive laws.

\begin{tabular}{ccccccc}
\hline & $h 1$ & $h 2$ & $h 3$ & $h 4$ & $h 5$ & $h 6$ \\
fcc & 1 & 1 & 1 & 0.83 & 0.83 & 0.83 \\
bcc110 & 1 & 1 & 1 & 0.83 & 0.83 & 0.83 \\
bcc112 & 1 & 1 & 0.83 & 0.83 & 0.83 & 0.83 \\
\hline
\end{tabular}

Table 2: Coefficients of the interaction matrix: $h_{1}:$ self hardening, $h_{2}:$ coplanar slip, $h_{3}$ : Hirth interactions, $h_{4}$ : collinear slip, $h_{5}$ : glissile slip, $h_{6}$ : Lomer locks (after Osipov et al. [2008].) 


\begin{tabular}{|c|c|c|c|c|}
\hline Material & Isotropic elasticity & \multicolumn{3}{|c|}{ Plasticity } \\
\hline Isotropic hard. & $E$ & $\overline{\sigma_{y}}$ & $\bar{Q}$ & $\bar{b}$ \\
\hline Austenite & $125 \quad 0.3$ & 200 & 73 & 343 \\
\hline Ferrite & $181 \quad 0.3$ & 295 & 150 & 186 \\
\hline Units & $\mathrm{GPa}$ & $\mathrm{MPa}$ & $\mathrm{MPa}$ & - \\
\hline Kinematic hard. & $\bar{E}$ & $\sigma_{y}$ & $\overline{C C}$ & $\overline{\bar{D}}$ \\
\hline Austenite & $\begin{array}{ll}125 & 0.3\end{array}$ & 201 & 19000 & 181 \\
\hline Ferrite & $181 \quad 0.3$ & 297 & 26000 & 130 \\
\hline Units & $\mathrm{GPa}$ & $\mathrm{MPa}$ & $\mathrm{MPa}$ & - \\
\hline
\end{tabular}

Table 3: Parameters of the macro-homogeneous (MH) constitutive laws (eq. 10 [11).

apparent (macroscopic) properties, to 85 for illustrating the local resolution capacities of the modelling. For each polycrystal, the nuclei are imposed to appear simultaneously at vertices of the parent polycrystal, chosen randomly, and their number is set to be about twice the number of parent grains. The new grains grow at a constant, uniform and isotropic rate.

$\rightarrow$ These choices correspond to a model configuration of phase transformation. Though they are arbitrary, they are potentially representative of an actual phase transformation. Indeed, the kinetics in an actual phase transformation is strongly influenced by thermomechanical factors such as pre-deformation Majta and Zurek [2003]; Xiao et al. [2006]; Mohapatra et al. [2007], cooling rate Huang et al. [2006]; Liu et al. [2006]; van Dijk et al. [2007], austenitization temperature Mecozzi et al. [2006a]. As a consequence, the ranges into which the kinetics parameters can fall are very wide and are thus very likely to include the retained model configuration. The characterization of the effects of these parameters on the product phase morphology and mechanical properties will be the subject of future works.

As explained previously, the reference simulations with $\mathrm{MH}$ constitutive laws are performed in the basic configuration of kinetics and microstructural morphology presented in Barbe et al. [2007]: the domain of simulation contains a single central nucleus which grows isotropically and at a constant rate.

Mesh discretization and simulation. A preliminary analysis, whose results are not presented herein for the sake of brevity, led us to choose a mesh discretization which depends on the scale under interest: about $14^{3}$ elements per product grain (or $18^{3}$ per parent grain) for the analysis of local fields with a single high-resolution simulation; about $9^{3}$ elements per product grain (or $10^{3}$ per parent grain) for the analysis of apparent properties and their dependence on material history. This case of study requires many simulations, differing in loadings as well as material properties; that is why the element density within each grain is chosen as small as possible, but still large enough to avoid any effect of this density. The absence of mesh size effect has been confirmed in two ways: first, by checking the convergence of the global-scale results for a stress-free transformation, and secondly by analysing the effect of material properties variation of the interphase region on the apparent properties, as explained in Section 2.2.2.

With hexahedral finite elements constituted of 8 nodes and 8 integration points, the simulations for the analysis of apparent properties can be performed in parallel within 
10 to 30 hours on 8 cores of a dual processor quad-core, depending on the loading case.

For the basic configuration of a single central macro-homogeneous particle growing into a macro-homogeneous matrix, the domain of simulation is meshed with $32 \times 32 \times$ 32 8-node hexahedral elements (such as for PX2PX modelling). This discretization has been proved to provide results which are insensitive to mesh size Barbe et al. [2007].

\subsection{Analysis}

\subsubsection{Local scale}

For a preliminary analysis of local fields arising from the interactions between parent and growing grains in a transforming polycrystal, the stress-free transformation from a 85 -grain polycrystal to a 177 -grain polycrystal is considered. The conjunction of these relatively large numbers of grains and of the chosen fine discretization $\left(80^{3}\right.$ elements) is intended to show the capacities of the modelling as regards the simulations of finely described representative polycrystalline volume elements. Fig. 7 depicts von Mises equivalent stress field and equivalent total strain field at $67 \%$ transformation. At this point, some of the new grains are finished growing, thus having polyhedral shapes, whereas some others are still in the process, thus showing more or less spherical shapes. For both kinds of new grains, stress and strain fields appear to be very heterogeneous at the intracrystalline scale, as is observed in elastoplastic polycrystals subjected to an external load Barbe et al. [2001b, 2009]. More specifically, highest stresses appear at the vicinity of boundaries between growing grains and parent grains, mostly in the product grains, which can sustain the highest stresses. This is significative of strong elastoplastic interactions due to the transformation itself. They result in accomodation strains in both phases. They are represented in two different pictures because of different orders; as compared to the total strain in the parent phase, the total strain in the product phase includes the supplementary transformation strain (equal to 0.0042). Taking into account this difference due to the transformation strain, it seems that strains are more heterogeneous in the product phase than in the parent phase. A systematic characterization of the heterogeneities in each phase, as performed in Barbe et al. [2007], would be necessary to put things into perspectives about this point.

\subsubsection{Global scale}

Three cases of histories are first considered for the analysis of apparent properties: virgin, FDT and $P H$ (see Section 3.1 for descriptions). Fig. 8 presents the time evolution of the slip activities on each of the three slip system families generating plastic strain: "parent FCC", "product BCC $\left\{\begin{array}{lll}1 & 1 & 0\end{array}\right\}$ " and "product BCC $\left\{\begin{array}{lll}1 & 1 & 2\end{array}\right\} "$.

The slip activity is defined by the sum of the slips on all the slip systems of the considered family. For convenience, the pre-hardening part of the test $P H$ is not represented in the diagrams. The large amount of slip which is generated in the parent material by this pre-hardening is set to zero in the diagram, so as to ease the comparison with the case of $F D T$ test. The transformation starts at $t=0$ and is followed, at $t=16$, by the post-tension (tension on the product material).

Each case of transformation history leads to slip activity during the transformation, about twice as large in the parent material as in the product material. This concords with the less rigid nature of the parent material. The type of hardening plays a role in the pre-hardened parent material: its slip activity is about twice as large with kinematic hardening as with isotropic hardening. This means that some of the shear stresses which have been activated by the pre-hardening have been reversed by the 


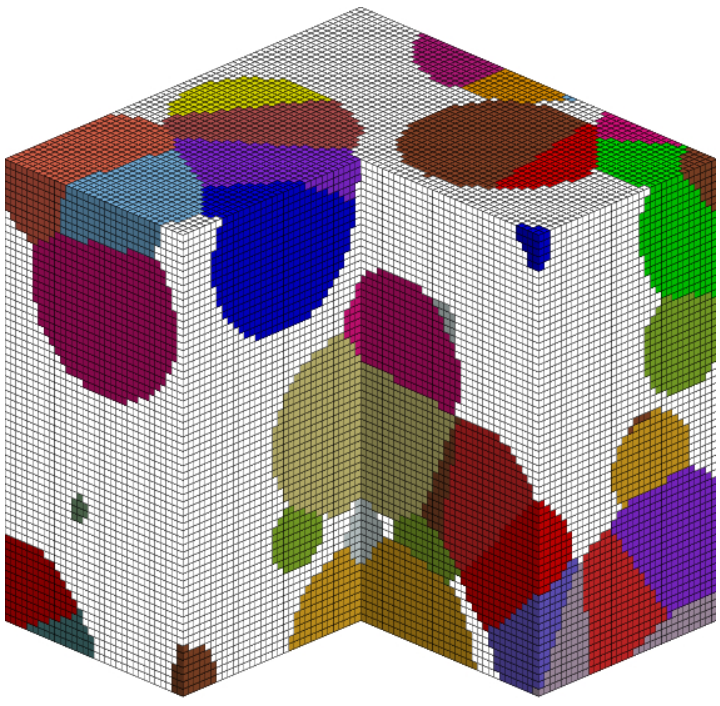

a)

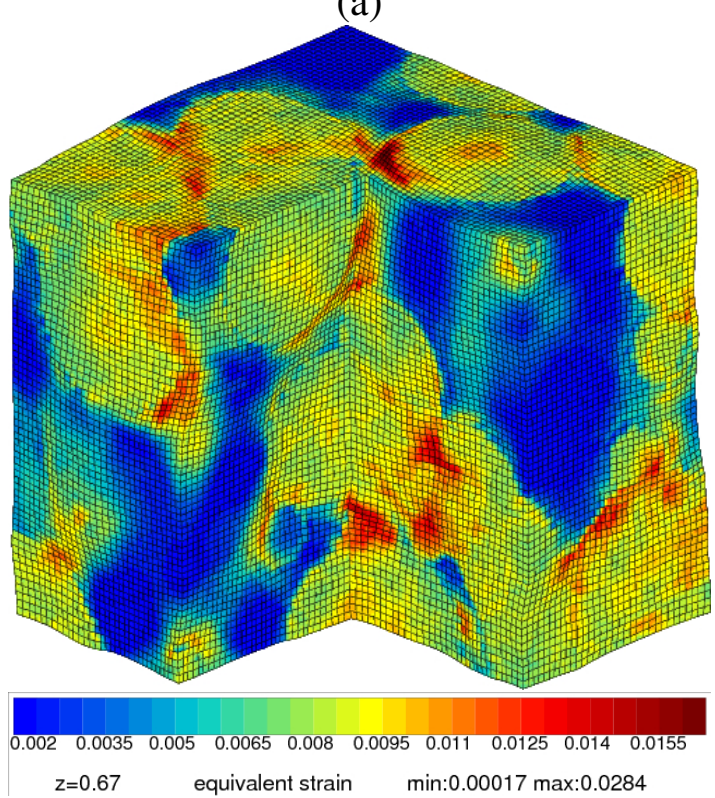

(c)

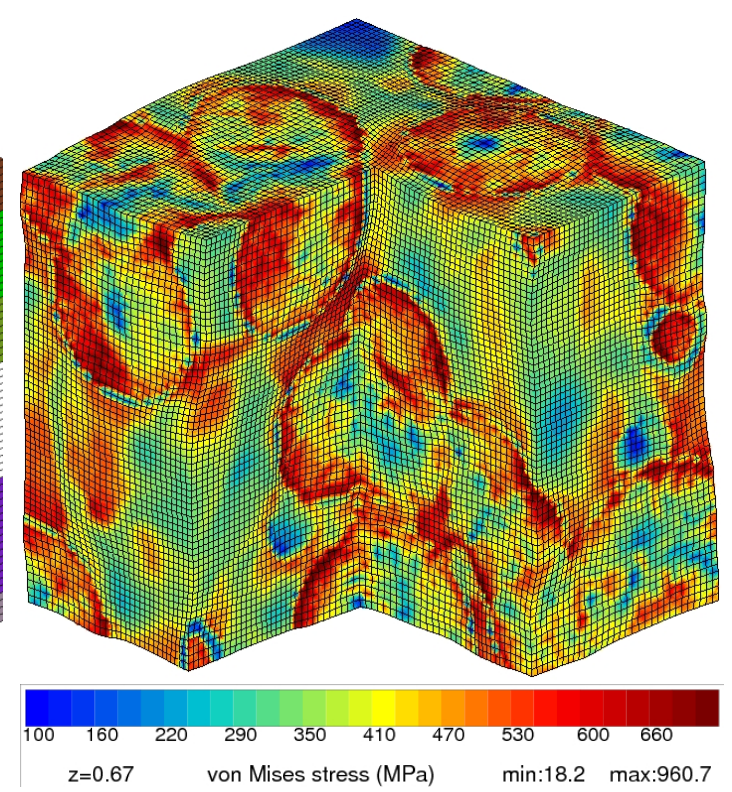

(b)

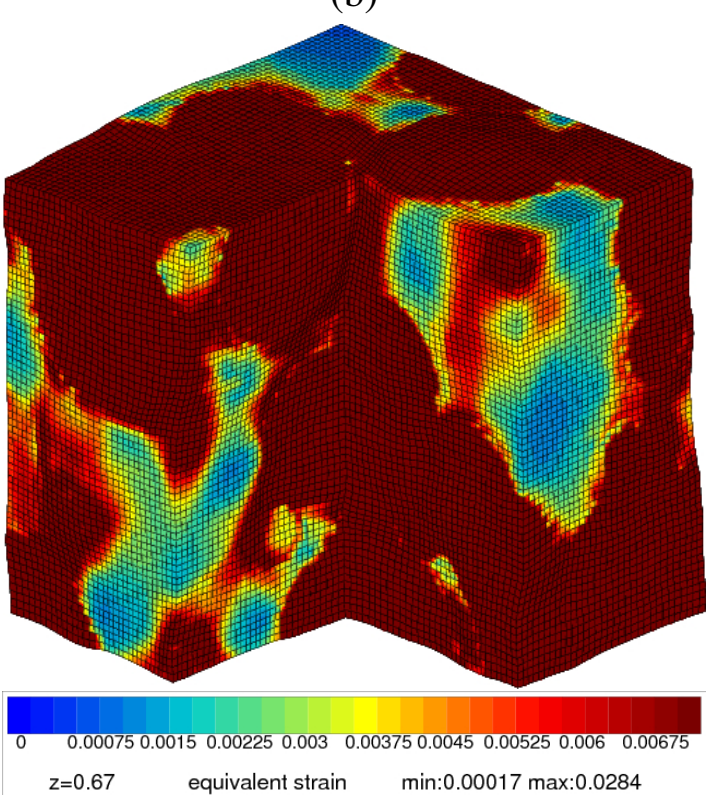

(d)

Figure 7: Stress-free transformation of a 85-grain austenite polycrystal to a 177-grain ferrite polycrystal discretized into $80^{3}$ brick elements. Volume fraction of ferrite is $z=0.67$. (a) Growing particles (parent grains are not represented). (b) Von Mises equivalent stress field. (c) Equivalent total strain field for ferrite (higher values) (d) Equivalent total strain field for austenite (lower values). Displacements are amplified and quarter of the polycrystal has been removed for visualisation sake. 
transformation, and, to go further, that local stresses generated by the stress-free transformation can be of the same order than those due to the pre-hardening.

Post-tension shows that whatever the hardening and the transformed material (FDT or $P H)$, the slip systems are activated in a range of strains which are elastic for the virgin material (from $t=16$ to $t=27$ ). As seen on Fig. 9a which provides the stress-strain curve of the post-tension, this early activity results in a pseudo-elasticity with a smaller rigidity than in the virgin material, which corresponds to a release of the internal stresses produced by the transformation. The last stage of the post-tension (plotted in the insets of Fig. 8) shows that pre-hardening itself does not affect the plastic regime of the product material: $P H$ and FDT post-tension curves do not differ significantly. On the contrary, as especially seen on the tensile curves of Fig.99, the transformation history does produce an effect, as well as the type of hardening; the softest material being obtained with kinematic hardening. The reasons for this phenomenon are similar to those explaining the effect of hardening on the parent slip activity.

MH constitutive laws, whose tensile stress-strain curves are shown in Fig. 9b, also lead to a release of transformation-induced internal stresses during the post-tension, but to a less extent and only at the early stages of plasticity. This time, the cases of transformed material ( $F D T$ and $P H$ ) with isotropic hardening present the hardest properties and shows at last that the product material seem to have inherited of part of the pre-hardening.

The effect of imposing a constant small stress (50 MPa) during the transformation (case CTRIP) can be analysed with the post-tension curves in Fig. 10. With the MH description of the phases, imposing an external load during the transformation does not affect the product phase tensile response. But it does with the PX2PX modelling: it leads to a softening of the product phase as regards the stress-free transformed material, especially with isotropic hardening.

At last, the evolution of TRIP obtained during the classical TRIP test (CTRIP) is considered according to the volume fraction of product phase in Fig. 10. The TRIP predicted with MH laws (considered as a reference since it is similar to that provided by a classical Leblond-type modelling) is about three times as large as the one predicted by PX2PX modelling. But the best qualitative agreement with experimentally measured TRIP is provided by PX2PX modelling. This is mainly related to the kinetics of transformation, as explained in Barbe et al. [2008]; Hoang et al. [2007]; Quey et al. [2009]: whereas the volume fraction of product phase evolves proportionally to $t^{3}$ with the MH modelling, it is described by a sigmoidal function (of the form $1-\exp \left(-a t^{b}\right)$ ) with PX2PX modelling, and thus better matchs real kinetics. It should also be recalled that the TRIP obtained from a microstructure-based modelling, i.e. with spatially irregular nucleation, strongly depends on the nucleation density and growth rate. Future investigations, from the viewpoints of experimental characterization or phase transformation modelling, will enable to get information on the actual nucleation and growth kinetics of real phase transformations.

\section{Conclusions}

A numerical modelling of polycrystal-to-polycrystal diffusive transformation taking into account microstructural morphology evolution and crystalline plasticity has been introduced. The kinetics is prescribed at the micro-scale of a polycrystalline aggregate such as to reproduce the principal characteristics of diffusive transformations 


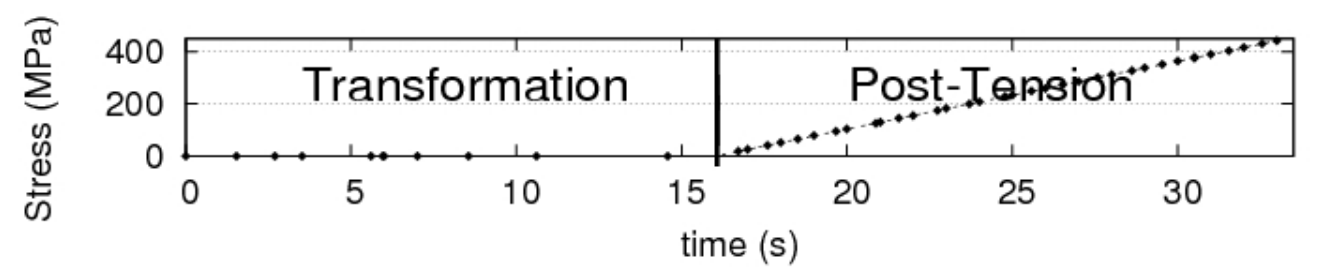

Figure 8: Evolution of the slip activity (equivalent amount of slip) in each slip system family according to time for three different specimens (virgin, stress-free transformed $(F D T)$ and pre-hardened $(P H)$ ) and for two kinds of hardenings (isotropic or kinematic). Details on the curves at the end of the post-tension are given in the insets. 


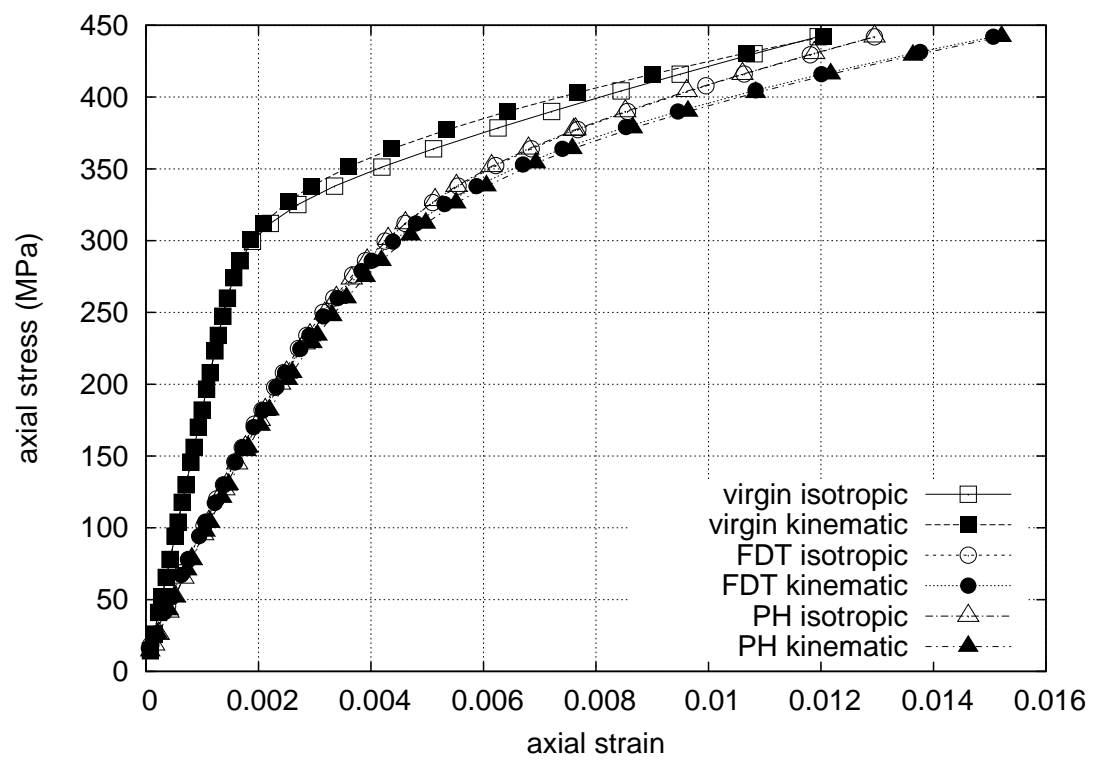

Figure 9: Tensile stress-strain curves of the three different specimens (virgin, stress-free transformed $(F D T)$ and pre-hardened $(\mathrm{PH})$ ) and for two kinds of hardenings (isotropic or kinematic). (a) PX2PX simulations, (b) MH modelling.

(a)

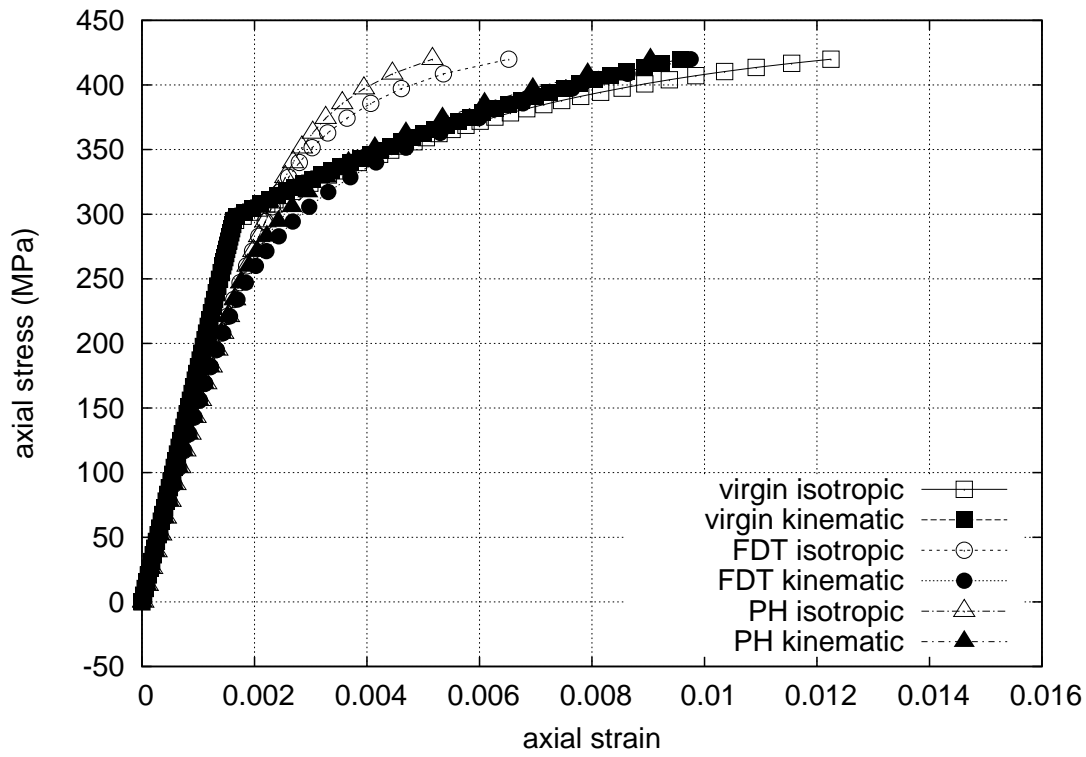

(b) 


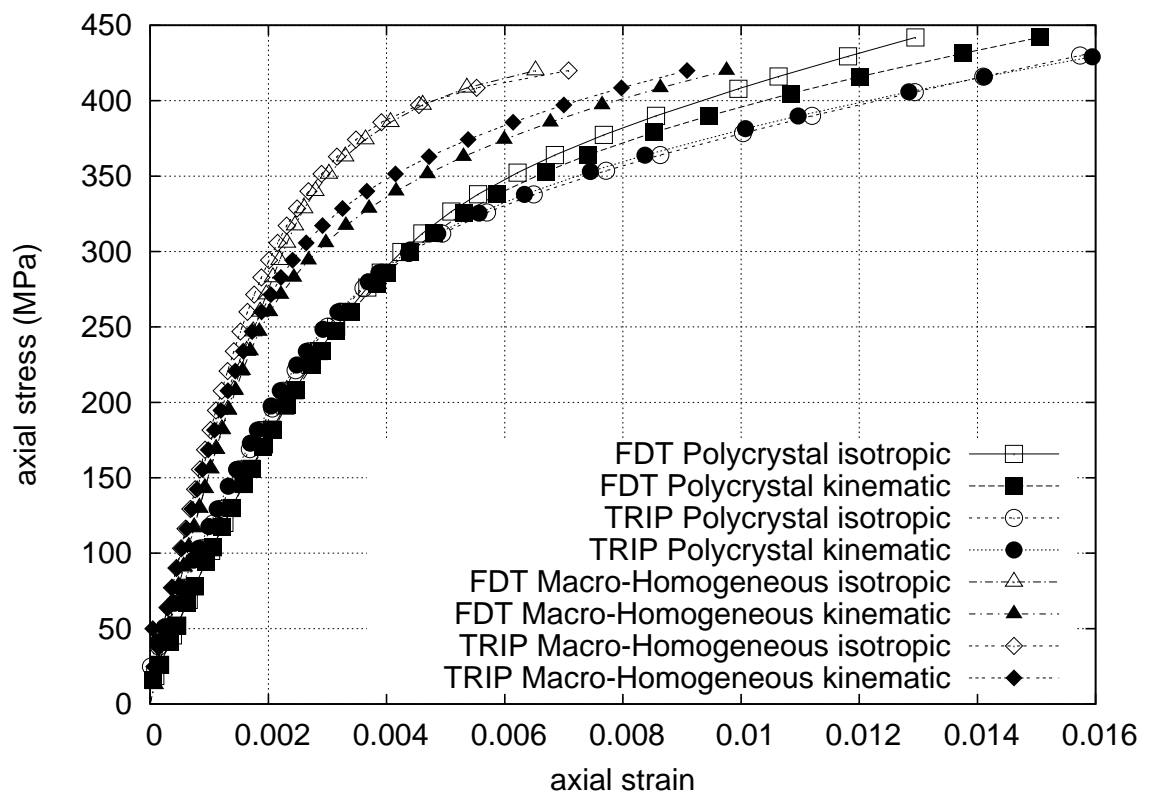

Figure 10: Comparison between $\mathrm{MH}$ and PX2PX simulations for two kinds of hardening (isotropic and kinematic). (a) Tensile stress-strain curves of the product material after a free-dilatometry test (FDT) or after a transformation under small constant stress $(C T R I P)$. (b) TRIP vs volume fraction of product phase, obtained from the classical TRIP test (CTRIP).

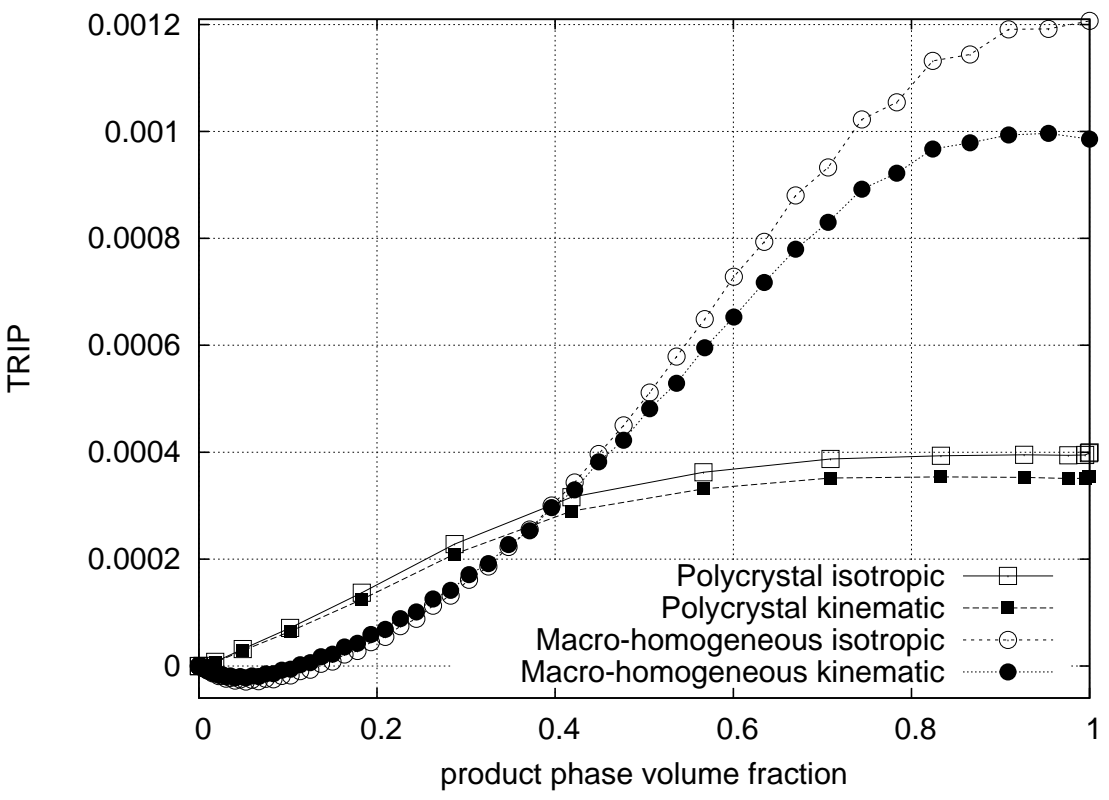

(b) 
in actual steels: nucleation at preferential sites of a polycrystal with random microstructural morphology, such as Voronoi tessellations; nucleation and growth laws depending on time. The problem of the elastoplastic interactions between parent and growing grains is solved by the FE method at the intracrystalline scale of a 3D representative volume element.

The proposed applications illustrate the principal features of the modelling in a model configuration: the local scale analysis leads to the conclusion that stress and strain fields can hardly be considered as homogeneous during or after a stress-free transformation, contrary to what is generally assumed. On the global scale, plasticity is observed to take place in each phase during the transformation and whatever the loading exerted prior to or during the latter. Contrary to a modelling based on macrohomogeneous modelling of phases, pre-hardening does not affect the product apparent properties, whatever the type of hardening used, but the transformation itself does: the elastic rigidity of a previously transformed polycrystal is remarkably reduced as regards its rigidity in a supposedly virgin state (free of internal stresses). This raises a fundamental question about the identification of material parameters from experiments: when identifying the elastoplastic properties of a product material at the temperature of its isothermal transformation, should they be considered by default as those of a material free of internal stresses or should one take into account its whole transformation history? Future works relating experiments to simulations and aiming at the assessment of the present modelling will bring out answers regarding the need of taking into account internal stress and strain fields resulting from phase transformation when modelling elastoplasticity of polycrystalline materials. $\gg$ An other important and challenging problem to be tackled concerns the imposed kinetics. Some of its characteristics might be quite easily identified from experimental observations (global kinetics, ratio between product and parent grains). But the others (regarding nucleation rate, distribution of nucleation sites, growth rate ...) require complex experimental equipments and procedures for their evaluations. Two other approaches can be thought of: an analysis of the sensibility of results to microstructural parameters and the use, at the local scale of few grains, of physics based numerical modelling of microstructural evolution.

\section{Acknowledgements}

This work was performed using HPC resources from GENCI-CINES (Grant 2010gpm6409).

\section{References}

Ammar, K., Appolaire, B., Cailletaud, G., Feyel, F., Forest, S., 2009a. Finite element formulation of a phase field model based on the concept of generalized stresses. Comput. Mat. Sc. 45, 800-805.

Ammar, K., Appolaire, B., Cailletaud, G., Forest, S., 2009b. Combining phase field approach and homogenization methods for modelling phase transformation in elastoplastic media. Eur. J. Comput. Mech., submitted.

Apel, M., Benke, S., Steinbach, I., 2009. Virtual dilatometer curves and effective young's modulus of a $3 \mathrm{~d}$ multiphase structure calculated by the phase-field method. Comput. Mater. Sci. 45, 589-592.

Artemev, A., Wang, Y., Khachaturyan, A., 2000. Three-dimensional phase field model and simulation of martensitic transformation in multilayer systems under applied stresses. Acta. Mater. 48 (10), 25032518 . 
Barbe, F., Decker, L., Jeulin, D., Cailletaud, G., 2001a. Intergranular and intragranular behavior of polycrystalline aggregates. Part 1: F.E. model. Int. J. Plasticity 17, 513-536.

Barbe, F., Forest, S., Cailletaud, G., 2001b. Intergranular and intragranular behavior of polycrystalline aggregates. Part 2: results. Int. J. Plasticity 17, 537-563.

Barbe, F., Forest, S., Cailletaud, G., 2001c. Polycrystalline plasticity under small strains. Toward finer descriptions of microstructures. In: E. Bouchaud et al (Ed.), NATO Proceedings, Physical Aspects of Fracture. Kluwer Academic Publishers, pp. 191-206.

Barbe, F., Quey, R., Musienko, A., Cailletaud, G., 2009. Three-dimensional characterization of strain localization bands in high resolution elastoplastic polycrystals. Mech. Res. Comm. 36, 762-768.

Barbe, F., Quey, R., Taleb, L., 2007. Numerical modelling of the plasticity induced during diffusive transformation. Case of a cubic array of nuclei. Eur. J. Mech., A/Solids 26, 611-625.

Barbe, F., Quey, R., Taleb, L., Souza de Cursi, E., 2005. Numerical determination of the effective TRIP during diffusive transformation in a volume with randomly positioned nuclei. In: H.-W. Zoch, Th. Lübben (Ed.), Proc 1st Int Conf Distortion Engineering. pp. 149-156.

Barbe, F., Quey, R., Taleb, L., Souza de Cursi, E., 2008. Numerical modelling of the plasticity induced during diffusive transformation. An ensemble averaging approach for the case of random arrays of nuclei. Eur. J. Mech., A/Solids 27, 1121-1139.

Besson, J., Leriche, R., Foerch, R., Cailletaud, G., 1998. Object-Oriented Programming Applied to the Finite Element Method. Part II. Application to Material Behaviors. Revue Européenne des Éléments Finis 7 (5), 567-588.

Canova, G. R., Wenk, H. R., Molinari, A., 1992. Deformation modelling of multi-phase polycrystals: case of quartz-mica aggregate. Acta Metall. Mater. 40 (7), 1519-1530.

Coret, M., Calloch, S., Combescure, A., 2004. Experimental study of the phase transformation plasticity of 16MND5 low carbon steel induced by proportional and nonproportional biaxial loading paths. Eur. J. Mech., A/Solids 23, 823-842.

Denis, S., Gautier, E., Sjöström, S., Simon, A., 1987. Influence of stresses on the kinetics of pearlitic transformation during continuous cooling. Acta Metall. 35, 1621-1632.

Diard, O., Leclercq, S., Rousselier, G., Cailletaud, G., 2005. Evaluation of finite element based analysis of 3D multicrystalline aggregates plasticity. Application to crystal plasticity model identification and the study of stress and strain fields near grain boundaries. Int. J. Plasticity 21, 691-722.

Fischer, F. D., 1990. A micromechanical model for transformation plasticity in steels. Acta Metall. Mater. 38, 1536-1546.

Fischer, F. D., Reisner, G., Werner, E., Tanaka, K., Cailletaud, G., Antretter, T., 2000. A new view on transformation induced plasticity (TRIP). Int. J. Plasticity 16, 723-748.

Franciosi, P., 1985. The Concepts of Latent Hardening and Strain Hardening in Metallic Single Crystals. Acta Metall. 33, 1601-1612.

Ganghoffer, J. F., Denis, S., Gautier, E., Simon, A., Sjöström, S., 1993. Finite element calculation of the micromechanics of a diffusional transformation. Eur. J. Mech., A/Solids 12 (1), 21-32.

Ganghoffer, J. F., Simonsson, K., 1998. A micromechanical model of the martensitic transformation. Mech. Mater. 27, 125-144.

Gaubert, A., Le Bouar, Y., Finel, A., 2009. Coupling phase field and visco-plasticity to study rafting in ni-base superalloys. Phil. Mag., In press.

Gautier, E., Simon, A., Beck, G., 1987. Plasticité de transformation durant la transformation perlitique d'un acier eutectoïde. Acta Metall. 35, 1367-1375.

Gérard, C., N'Guyen, F., Osipov, N., Cailletaud, G., Bornert, M., Caldemaison, D., 2009. Comparison of experimental results and finite element simulation of strain localization scheme under cyclic loading. Comput. Mater. Sci. 46, 755-760.

Gourgues, A., 2007. Application of electron backscatter diffraction to the study of phase transformations. Int. Mater. Rev. 52 (2), 65-128.

Grostabussiat, S., Taleb, L., Jullien, J. F., 2004. Experimental results on classical plasticity of steels subjected to structural transformations. Int. J. Plasticity 20 (8-9), 1371-1386.

Hoang, H., May 27th 2008. Modélisation numérique de la plasticité des transformations de phase diffusives à l'état solide. Ph.D. thesis, INSA Rouen.

Hoang, H., Barbe, F., Quey, R., Taleb, L., 2007. FE determination of the plasticity induced during diffusive transformation in the case of nucleation at random locations and instants. Comput. Mater. Sci. 43, 101-107.

Huang, C.-J., Browne, D. J., McFadden, S., 2006. A phase-field simulation of austenite to ferrite transformation kinetics in low carbon steels. Acta Mater. 54 (1), 11-21. 
Inoue, T., Wang, Z., 1985. Coupling between stress, temperature, and metallic structures during processes involving phase transformations. Mater. Sc. Technol. 1, 845-849.

Iwamoto, T., Cherkaoui, M., Busso, E., 2008. A finite element-based level-set method of an interface motion driven by adiffusion field: Application to a phase transformation problem. Comput. Mater. Sci. 44, 792-801.

Kempen, A. T. W., Sommer, F., Mittermeijer, E. J., 2002. The kinetics of the autenite-ferrite phase transformation of Fe-Mn: differential thermal analysis during cooling. Acta Mater. 50, 3545-3555.

Lan, Y., Xiao, N., Li, D., Li, Y., 2005. Mesoscale simulation of deformed austenite decomposition into ferrite by coupling a cellular automaton method with a crystal plasticity finite element model. Acta Mater. 53 (4), 991-1003.

Landheer, H., Offerman, S., Petrov, R., Kestens, L., 2009. The role of crystal misorientations during solid-state nucleation of ferrite in austenite. Acta Mater. 57, 1486-1496.

Lebensohn, R., Montagnat, M., Mansuy, P., Duval, P., Meysonnier, J., Philip, A., 2009. Modeling viscoplastic behavior and heterogeneous intracrystalline deformation of columnar ice polycrystals. Acta Mater. 57, 1405-1415.

Leblond, J. B., 1989. Mathematical modelling of transformation plasticity in steels II: coupling with strain hardening phenomena. Int. J. Plasticity 5, 573-591.

Leblond, J. B., Devaux, J., Devaux, J. C., 1989. Mathematical modelling of transformation plasticity in steels I: case of ideal-plastic phases. Int. J. Plasticity 5, 551-572.

Leblond, J. B., Mottet, G., Devaux, J. C., 1986. A theoretical and numerical approach to the plastic behavior of steels during phase transformations I: derivation of general relations. J. Mech. Phys. Sol. 34 (4), 395-409.

Lecroisey, F., Pineau, A., 1972. Martensitic Transformations Induced by Plastic Deformation in the Fe-Ni-Cr-C System. Metall. Trans. 3, 387-396.

Lee, M.-G., Kim, S.-J., Han, H. N., 2010. Crystal plasticity finite element modeling of mechanically induced martensitic transformation (mimt) in metastable austenite. Int. J. Plasticity 26 (5), 688-710.

Levitas, V., Lee, D.-W., 2007. Athermal resistance to an interface motion in phase field theory of microstructure evolution. Phys. Rev. Let. 99, 245701.

Levitas, V. I., Lee, D.-W., Preston, D. L., 2010. Interface propagation and microstructure evolution in phase field models of stress-induced martensitic phase transformations. Int. J. Plasticity 26 (3), 395422.

Liu, Y., Sommer, F., Mittemeijer, E., 2006. The austenite-ferrite transformation of ultralow-carbon fe-c alloy; transition from diffusion- to interface-controlled growth. Acta Mater. 54 (12), 3383-3393.

Mahnken, R., Schneidt, A., Antretter, T., 2009. Macro modelling and homogenization for transformation induced plasticity of a low-alloy steel. Int. J. Plasticity 25, 183-204.

Majta, J., Zurek, A. K., 2003. Modeling of ferrite structure after deformation in the two-phase region. Int. J. Plasticity 19 (5), 707-730.

Manchiraju, S., Anderson, P., 2010. Coupling between martensitic phase transformations and plasticity: A microstructure-based finite element model. Int. J. Plasticity, In Press, Corrected Proof.

Mecozzi, M. G., Sietsma, J., van der Swaag, S., 2006a. Analysis of $\gamma \longrightarrow \alpha$ transformation in a Nb micro-alloyed C-Mn steel by phase field modelling. Acta Mater. 54, 1431-1440.

Mecozzi, M. G., Sietsma, J., van der Swaag, S., 2006b. Phase field modelling of the interfacial condition at the moving interphase during the $\gamma \longrightarrow \alpha$ transformation in C-Mn steels. Comput. Mater. Sci. 34, 290-207.

Meftah, S., Barbe, F., Taleb, L., Sidoroff, F., 2007. Parametric Numerical Simulations of TRIP and its Interaction with Classical Plasticity in Martensitic Transformation. Eur. J. Mech., A/Solids 26 (4), 688-700.

Méric, L., Poubanne, P., Cailletaud, G., 1991. Single Crystal Modeling for Structural Calculations. Part 1: Model Presentation. J. Eng. Mater. Technol. 113, 162-170.

Mohapatra, G., Sommer, F., Mittemeijer, E., 2007. The austenite to ferrite transformation of fe-ni under the influence of a uniaxially applied tensile stress. Acta Mater. 55 (13), 4359-4368.

Musienko, A., Cailletaud, G., 2009. Simulation of inter- and transgranular crack propagation in polycrystalline aggregates due to stress corrosion cracking. Acta Mater. 57, 3840-3855.

Musienko, A., Tatschl, A., Schmidegg, K., Pippan, R., Kolednik, O., Cailletaud, G., 2007. Threedimensional finite element simulation of a polycrystalline copper specimen. Acta Mater. 55, 41214136.

Nagayama, K., Terasaki, T., Tanaka, K., Fischer, F., Antretter, T., Cailletaud, G., Azzouz, F., 2001. Mechanical properties of a Cr-Ni-Mo-Al-Ti maraging steel in the process of martensitic 
transformation. Mater. Sci. Eng. A 308, 25-37.

Neper, 2007. Neper: a software to generate 3D random polycrystals for the finite element method (version 1.6). http://neper.sourceforge.net.

Nygards, M., Gudmundson, P., 2002. Three-dimensional periodic Voronoi grain models and micromechanical FE-simulations of a two-phase steel. Comput. Mater. Sci. 24, 513-519.

Offerman, S. E., van Dijk, N. H., Sietsma, J., Lauridsen, E. M., Margulies, L., Grigull, S., Poulsen, H. F., van der Zwaag, S., 2006. Phase transformations in steel studied by 3DXRD microscopy. Nuclear Instruments and Methods in Physics Research B 246, 194-200.

Offerman, S. E., van Wilderen, L. J. G. W., van Dijk, N. H., Sietsma, J., Rekveldt, M. T., van der Zwaag, S., 2003. In-situ study of pearlite nucleation and growth during isothermal austenite decomposition in nearly eutectoid steel. Acta Mater. 51, 3927-3938.

Olson, G., Cohen, M., 1975. Kinetics of Strain-Induced martensitic nucleation. Metall. Trans. A 6A, 791-795.

Osipov, N., Gourgues-Lorenzon, A., Marini, B., Mounoury, V., N'Guyen, F., Cailletaud, G., 2008. FE modelling of bainitic steels using crystal plasticity. Phil. Mag. 88 (30), 3757-3777.

Quey, R., Barbe, F., 2007. Free meshing of microstructures based on modified Voronoi tessellations. In: 17th Int Workshop Computational Mechanics of Materials. Paris (France), August 22-24.

Quey, R., Hoang, H., Barbe, F., Taleb, L., 2009. Effect of the random spatial distribution of nuclei on the transformation plasticity in a diffusively transforming steel. Int. J. Microstructure Materials Property, To appear.

Sai, K., Cailletaud, G., Forest, S., 2006. Micro-mechanical modeling of the inelastic behavior of directionally solidified materials. Mech. Mater. 38, 203-217.

Schmidt, S., Olsen, U., Poulsen, H., Sørensen, H., Lauridsen, E., Margulies, L., Maurice, C., Juul Jensen, D., 2008. Direct observation of 3-D grain growth in Al-0.1\% Mn. Scripta Mater. 59, 491-494.

Schuh, C., Dunand, D. C., 2001. Non-isothermal transformation-mismatch plasticity: modeling and experiments on Ti-6Al-4V. Acta Mater. 49, 199-210.

Suiker, A., Turteltaub, S., 2007. Numerical modelling of transformation-induced damage and plasticity in metals. Modelling Simul. Mater. Sci. Eng. 15, S147-S166.

Taleb, L., Petit, S., 2006. New investigations on transformation induced plasticity and its interaction with classical plasticity. Int. J. Plasticity 22, 110-130.

Taleb, L., Sidoroff, F., 2003. A micromechanical modeling of Greenwood-Johnson mechanism in transformation induced plasticity. Int. J. Plasticity 19 (10), 1821-1842.

Thiessen, R., Sietsma, J., Palmer, T., Elmer, J., Richardson, I., 2007. Phase-field modelling and synchrotron validation of phase transformations in martensitic dual-phase steel. Acta Mater. 55, 601614.

van Dijk, N., Offerman, S., Sietsma, J., van der Zwaag, S., 2007. Barrier-free heterogeneous grain nucleation in polycrystalline materials: The austenite to ferrite phase transformation in steel. Acta Mater. 55 (13), 4489-4498.

Videau, J. C., Cailletaud, G., Pineau, A., 1995. Experimental study of the transformation induced plasticity in Cr-Ni-Mo-Al-Ti steel. J. Phys. IV 6, 465-474.

Wolff, M., Böhm, M., Dalgic, M., Löwisch, G., Rath, J., 2007. Validation of a TRIP model with backstress for the pearlitic transformation of the steel 100Cr6 under step-wise loads. Comput. Mater. Sci. 39, 49-54.

Xiao, N., Tong, M., Lan, Y., Li, D., Li, Y., 2006. Coupled simulation of the influence of austenite deformation on the subsequent isothermal austenite-ferrite transformation. Acta Mater. 54 (5), 12651278.

Zeghadi, A., Forest, S., Gourgues, A., Bouaziz, O., 2007. Ensemble averaging stress-strain fields in polycrystalline aggregates with a constrained surface microstructure - Part 2: crystal plasticity. Phil. Mag. 87, 1425-1446.

Zhang, M., Kelly, P., 2009a. Crystallographic Features of Phase Transformations in Solids. Prog. Mater. Sci., In press.

Zhang, M., Kelly, P., 2009b. The morphology and formation mechanism of pearlite in steels. Materials Characterization 60, 545-554.

Zhao, Y., Tryon, R., 2004. Automatic 3-D simulation and micro-stress distribution of polycrystalline metallic materials. Comput. Meth. Appl. Mech. Eng. 193, 3919-3934.

Zheng, C., Xiao, N., Hao, L., Li, D., Li, Y., 2009. Numerical simulation of dynamic strain-induced austenite-ferrite transformation in a low carbon steel. Acta Mater. 57, 2956-2968. 